Revta brasil. Bot., São Paulo, V.23, n.3, p.231-253, set. 2000

\title{
Composição florística e estrutura fitossociológica de uma floresta ripária em Itutinga, MG, e comparação com outras áreas
}

\author{
EDUARDO VAN DEN BERG ${ }^{1,3}$ e ARY T. OLIVEIRA-FILHO ${ }^{2}$
}

(recebido em 24 de fevereiro de 1999; aceito em 15 de março de 2000)

\begin{abstract}
Floristic composition and phytosociological structure of a riparian forest in Itutinga, State of Minas Gerais, Brazil, and comparisons with other areas). The floristic composition and phytosociological structure were investigated in an area of 7.55 ha of a riparian forest in Itutinga, State of Minas Gerais, Southeastern Brazil. This forest locates alongside a narrow creek, and is sharply bounded by montane grasslands. The phytosociological survey was done on 28 plots of $10 \times 30 \mathrm{~m}$ where all individuals with diameter at the base of the trunk equal to or larger than $5 \mathrm{~cm}$ were recorded and had their diameter measured and height estimated. The floristic survey was based on specimens collected both in and outside the plots. The study area was compared with other forests of São Paulo and Minas Gerais States using multivariate analyses. The floristic survey recorded 162 species and 54 families. The forests with flora most similar to the study area were those in the same region (upper rio Grande). We suggest rainfall seasonality and altitude as the variables most strongly influencing the floristic differences among the forests compared. The phytosociological survey recorded 2145 individuals in 141 species. The highest structural similarities occurred with forests in Itutinga and Bom Sucesso, followed by Madre de Deus and Poço Bonito. We suggest differences and similarities in soil properties, topographic features and the occurrence of seasonal floods as the main variables influencing the pattern of similarity observed.
\end{abstract}

RESUMO - (Composição florística e estrutura fitossociológica de uma floresta ripária em Itutinga, MG, e comparação com outras áreas). A composição florística e a estrutura fitossociológica foram investigadas em uma área de 7,55 ha de floresta ripária em Itutinga, MG. Essa floresta acompanha um pequeno curso d'água e tem limites bem definidos com um campo limpo montano. O levantamento fitossociológico foi realizado em 28 parcelas de 10 × $30 \mathrm{~m}$, onde todos os indivíduos com diâmetro do tronco à altura do solo igual ou maior que $5 \mathrm{~cm}$ foram registrados, tendo seus diâmetros medidos e alturas estimadas. O levantamento florístico baseou-se em coletas dentro e fora das parcelas. Encontraram-se 162 espécies pertencentes a 54 famílias. A área de estudos foi comparada com outras florestas dos Estados de São Paulo e Minas Gerais por meio de análises multivariadas. As áreas floristicamente mais semelhantes com a floresta estudada foram as da mesma região (alto rio Grande). Sugeriu-se que as variáveis mais fortemente ligadas à diferenciação florística entre as florestas comparadas sejam a estacionalidade das chuvas e a altitude. No levantamento fitossociológico, foram registrados 2145 indivíduos distribuídos em 141 espécies. As maiores semelhanças estruturais ocorreram com as florestas de Itutinga e Bom Sucesso e as maiores diferenças com Madre de Deus e Poço Bonito, diferenças que podem ser decorrentes de variações de propriedades dos solos.

Key words - Riparian forest, gallery forest, floristic composition, phytosociological structure, floristic and structural comparisons

\section{Introdução}

Florestas ripárias ou ripícolas são formações vegetais extremamente importantes em termos ecológicos, sendo essenciais para a manutenção da qualidade da água dos rios e da fauna ictiológica (CESP 1987). Segundo Redford \& Fonseca (1986), tais florestas são, também, essenciais para a sobrevivência da fauna de mamíferos das regiões do cerrado e da caatinga, provendo refúgio, água e alimento. Os autores salientaram, ainda, que aquelas florestas funcionam como corredores de penetração no cerrado

1. Departamento de Biologia, Universidade Federal de Lavras, Caixa Postal 37, 37200-000 Lavras, MG, Brasil.

2. Departamento de Ciências Florestais, Universidade Federal de Lavras, Caixa Postal 37, 37200-000 Lavras, MG, Brasil.

3. Autor para correspondência: evandenb@esal.ulfa.br para espécies de animais provenientes da Floresta Amazônica e Mata Atlântica, levando a uma importante permuta genética (fluxo gênico). Costa et al. (1992) fizeram observação semelhante sobre a expansão para o interior do país das espécies da flora silvícola que são dispersas por animais.

Apesar de sua inegável importância ambiental, tais florestas vêm sendo erradicadas em várias partes do Brasil. Entre os inúmeros fatores que têm contribuído para isto, destacam-se, pela gravidade, as derrubadas, os incêndios, os represamentos e o assoreamento dos rios devido à erosão (Gibbs et al. 1980). Florestas ripárias, por alojarem-se no fundo dos vales, são sistemas particularmente frágeis em relação a erosão, sedimentação do cursos d'água e outros impactos causados pelo homem nas bacias hidrográficas. Além disso, como o fundo dos vales comumente contém os solos mais férteis de uma 
bacia, estas florestas são as mais propensas a serem derrubadas para fins agrícolas.

A situação crítica dessas formações no centrosul do Brasil impulsionou, nos últimos anos, uma série de iniciativas voltadas para sua conservação ou recuperação. Tais iniciativas levaram aos simpósios sobre matas ciliares, o primeiro deles realizado em São Paulo, em 1989 (Barbosa 1989), e o segundo, em Ribeirão Preto, em 1995. Tais eventos deixaram claro para os pesquisadores interessados que estudos detalhados sobre a composição florística e a ecologia dos remanescentes dessas florestas são fundamentais para embasar quaisquer iniciativas para proteger, enriquecer, recuperar ou reconstituir esse tipo de vegetação.

Comparações florísticas entre as florestas do alto rio Grande (região do presente estudo) com outras florestas da região sudeste do Brasil têm mostrado que o componente higrófilo, juntamente com a altitude, pode ser um fator importante para a explicação dos padrões de (dis)similaridade (Carvalho et al. 1992, Gavilanes et al. 1992a, b). No entanto, Oliveira-Filho et al. (1994d), a partir da comparação entre 30 áreas da região sudeste (muitas não ripárias) concluiram que a altitude, ao determinar variações climáticas, é talvez o fator mais fortemente relacionado com a diferenciação florística das florestas semideciduais da região. Diferenças na estacionalidade das chuvas e a ocorrência nas margens de cursos d'água exerceriam papéis secundários, mas também importantes.

Levantamentos estritamente florísticos permitem comparações relativamente simples e eficientes entre um grande número de áreas. Porém, diferenças e semelhanças entre áreas geograficamente próximas e/ou floristicamente parecidas podem ser melhor abordadas através de dados quantitativos fornecidos por levantamentos fitossociológicos, pois diferenças quantitativas entre áreas podem ser muito mais marcantes que diferenças florísticas (Causton 1988). Medidas de abundância e de distribuição das espécies são essenciais, quando se objetiva conhecer a estrutura da vegetação e construir uma base teórica que subsidie seu manejo, conservação ou a recuperação de áreas similares (Vilela et al. 1993).

Os objetivos deste trabalho foram conhecer: a) a composição florística e a estrutura de uma floresta associada a um pequeno curso d'água (floresta ripá- ria), localizada no município de Itutinga, Estado de Minas Gerais; e b) seu grau de semelhança florísticoestrutural com outras florestas do sudeste do Brasil.

\section{Material e métodos}

Área de estudo - A área estudada (figura 1) apresenta-se como uma floresta alojada no fundo de um vale, acompanhando um pequeno córrego tributário do reservatório de Camargos. Este reservatório, formado pelo represamento do rio Grande, pertence à Companhia Energética de Minas Gerais (CEMIG). A floresta possui uma área de 7,55 ha e está localizada no município de Itutinga, MG, próxima das coordenadas $21^{\circ} 21^{\prime} \mathrm{S}$ e $44^{\circ} 36^{\prime} \mathrm{W}$, a cerca de $920 \mathrm{~m}$ de altitude. A partir deste ponto, a área de estudo será denominada Mata de Camargos, ou simplesmente Camargos.

Florestas associadas a cursos d'água são tratadas na literatura com uma nomenclatura tão variada quanto confusa. Floresta (ou mata) ciliar, de galeria, de várzea, ribeirinha e ripária (ripícola) estão entre as denominações mais comumente utilizadas. Este uso controvertido deve-se, em grande parte, à enorme variação das próprias condições ecológicas em que tal tipo de floresta pode ser encontrado no território brasileiro, bem como ao emprego de termos regionais. Mantovani (1989) sugeriu que se restringisse o uso de cada nome à sua aplicação original, tanto do ponto de vista ecológico quanto regional. Neste trabalho, considerou-se ripária ou ripícola qualquer floresta associada a cursos d'água, independentemente de sua composição florística, estrutura ou fisionomia. A área de estudos pode ser considerada uma floresta ripária, já que sua presença na área é claramente condicionada pela existência de um curso d'água, pois apresenta-se como uma faixa estreita ao longo do córrego, circundada por um campo limpo de altitude.

O sistema de classificação da vegetação brasileira do IBGE (Veloso et al. 1991) só reconhece a existência de florestas de

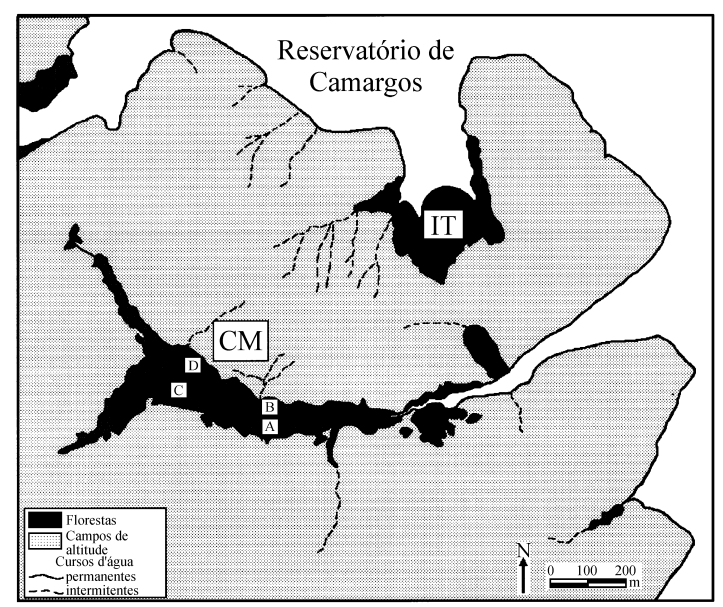

Figura 1. Mapa da área de estudos indicando a localização dos blocos de parcelas (A, B, C e D) na floresta ripária $(\mathrm{CM})$ estudada na região do reservatório de Camargos, Itutinga, MG. IT = fragmento florestal estudado por Oliveira-Filho et al. (1994c) e referido no presente trabalho. 
galeria nas regiões fito-ecológicas da savana (cerrados do Brasil central), da savana estépica (domínio das caatingas) e estepe (campanhas gaúchas). A área de estudo encontra-se em uma região considerada como disjunção da vegetação de savanas, onde predominam o campo e o campo cerrado (IBGE 1993). Assim, esta deve ser considerada como floresta de galeria no sistema de classificação do IBGE, já que acompanha um curso d'água e possui limites bem definidos com uma formação não florestal (Mantovani et al. 1989), no caso, um campo limpo de altitude. Como outras florestas da região, a deciduidade das árvores na área de estudo durante a estação seca atinge entre 20 e $50 \%$ dos indivíduos.

A área é um bom exemplo das florestas de galeria que normalmente se estendem ao longo dos cursos d'água que percorrem os campos de altitude da região do reservatório de Camargos. É relativamente próxima da base de apoio, em Lavras, MG (cerca de $50 \mathrm{~km}$ ). Há um bom conhecimento taxonômico das espécies florestais da região. Aparenta estar em bom estado de conservação. Não há sinais evidentes de exploração seletiva de madeira e os maiores danos observados devem-se à penetração do gado na floresta em busca de sombra e água, formando trilhas e prejudicando a vegetação do sobosque em alguns pontos. A borda da floresta está sujeita aos efeitos do fogo, ateado periodicamente no campo limpo circundante, para melhorar sua qualidade como pastagem. O limite abrupto entre estes dois tipos de vegetação coincide normalmente com o máximo alcance do fogo.

O clima da região é do tipo Cwb de Köppen, com verões úmidos e invernos secos (Eidt 1968). Dados provenientes da Estação Meteorológica de Lavras ( $21^{\circ} 14^{\prime} 06^{\prime}$ 'S e $45^{\circ} \mathrm{W}, 918 \mathrm{~m}$ de altitude), no período 1960-1992 revelam uma temperatura média anual de 19,6 $\pm 0,6{ }^{\circ} \mathrm{C}$, com as médias mensais variando de $16,03{ }^{\circ} \mathrm{C}$, em julho, a $21,82{ }^{\circ} \mathrm{C}$, em fevereiro; precipitação anual média de $1517 \pm 168 \mathrm{~mm}$ concentrados $(93 \%$ do total) na primavera/verão (outubro-março) e precipitações médias mensais variando de $19 \mathrm{~mm}$ (julho) a $293 \mathrm{~mm}$ (janeiro).

Os solos da área foram classificados através de perfis. Predominaram Cambissolos, compreendendo as áreas mais declivosas (blocos de parcelas A, B e D, figura 2). Latossolo variação Una ocorreu na área mais plana (bloco C, figura 2). O material de origem predominante é micaxisto. Não há presença de solos aluviais na área. O córrego apresenta variação muito pequena do seu nível durante todo o ano e não ocorrem inundações. A declividade média da área amostrada é de cerca de 7,75\% (medida com um clinômetro).

Levantamento florístico - Em 28 parcelas de 10 x 30 m, foram coletados todos os arbustos e árvores com DNS (diâmetro do caule no nível do solo) $\geq 5 \mathrm{~cm}$. Coletaram-se, também, espécimes em fase reprodutiva fora das parcelas. O período de coleta estendeu-se de fevereiro de 1993 a maio de 1994, com visitas mensais. O material botânico coletado foi herborizado e incorporado ao Herbário do Departamento de Biologia da Universidade Federal de Lavras (Herbário ESAL). As identificações foram feitas através de obras clássicas e revisões, comparações com exsicatas já identificadas existentes neste herbário ou no Herbário da Universidade Estadual de Campinas (UEC) e/ou através de consultas a especialistas.

Levantamento fitossociológico - As 28 parcelas foram distribuídas em quatro blocos (figura 1) e dispostas segundo a figura 2, procurando amostrar as variações mais evidentes: borda da floresta (Borda), margem do ribeirão (Margem) e área intermediária
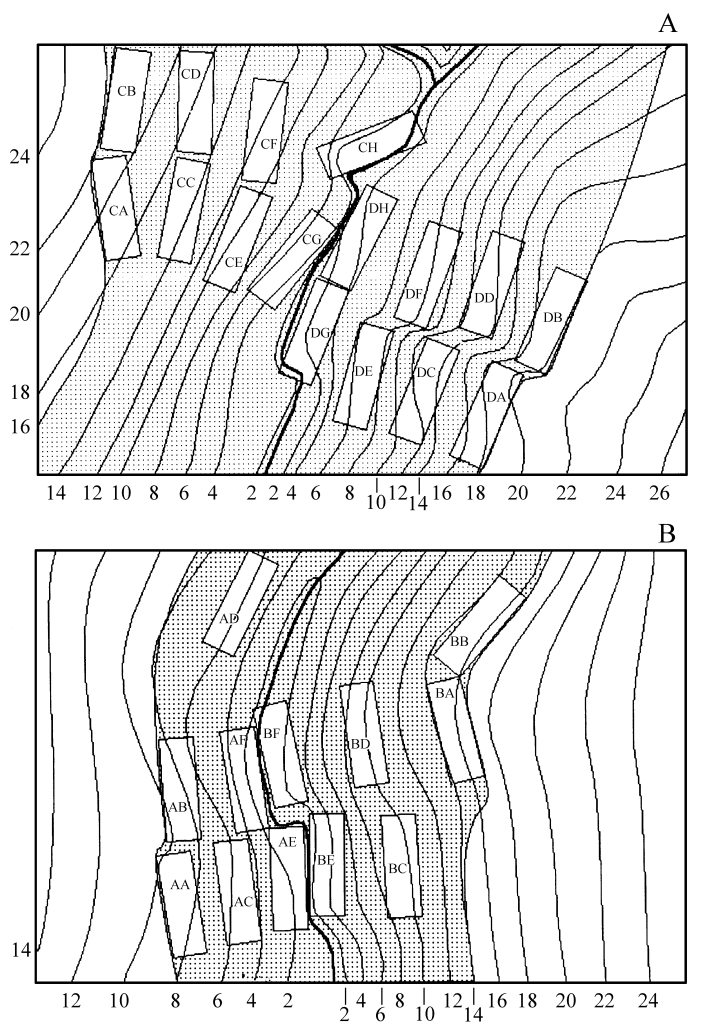

Figura 2. Distribuição das parcelas nos quatro blocos amostrais na floresta estudada na região do reservatório de Camargos, município de Itutinga, $\mathrm{MG}$. A. Blocos $\mathrm{C}$ (parcelas $\mathrm{CA}$ a CH) e D (parcelas DA a DH); B. Blocos A (parcelas AA a AF) e B (parcelas $\mathrm{BA}$ a $\mathrm{BF}$ ). Curvas de nível traçadas a intervalos de $2 \mathrm{~m}$ de altura vertical a partir da lâmina d'água do córrego. Área hachurada: floresta; Área não hachurada: campo de altitude.

(Meio). Os blocos A + B e C + D foram colocados de forma a amostrar dois trechos diferentes da floresta, um mais estreito e outro mais largo, respectivamente. $\mathrm{Na}$ área dos blocos $\mathrm{C}$ e $\mathrm{D}$, foi marcado um par a mais de parcelas de Meio, em cada bloco, devido à maior largura da floresta. A forma retangular da parcela obedeceu ao princípio expresso por Causton (1988) que parcelas retangulares cujo maior comprimento seja perpendicular à direção do gradiente principal são mais adequadas para estimar os parâmetros da vegetação. Desta maneira, há maior homogeneidade interna da parcela em relação ao gradiente conhecido, diminuindo as chances de que a parcela fique restrita a uma mancha de fatores ambientais desconhecidos. A marcação no campo foi feita de tal forma que as parcelas de cada par ficassem próximas umas da outras e que cada par estivesse o mais eqüidistante possível um do outro. O indivíduos nas parcelas foram marcados com plaquetas de alumínio numeradas. O valor relativamente baixo do diâmetro mínimo foi escolhido de forma a abranger vários estratos da comunidade arbóreo-arbustiva e não só os componentes do dossel superior. Este critério foi adotado, também, por ser igual ao utilizado nos levantamentos fitossociológi$\cos$ das florestas da região alto rio Grande, nos trabalhos do 
contrato CEMIG/UFLA/FAEPE (Oliveira-Filho et al. 1994a, b, c, e, Oliveira-Filho et al. 1995), facilitando comparações. A CNS (circunferência no nível do solo), medida com uma trena, e a altura, estimada por comparação com uma vara graduada de coleta de $6 \mathrm{~m}$, de cada indivíduo foram anotadas em uma planilha de campo. Os DNSs foram calculados a partir das CNSs.

Análise dos dados - Foram selecionadas 24 listas florísticas de áreas de floresta nos estados de Minas Gerais e São Paulo para realizar as comparações florísticas (tabela 2, figura 3). Foram escolhidas apenas aquelas listas que apresentassem um bom nível de identificação taxonômica. Além do mais, as comparações restringiram-se às florestas semelhantes à área de estudos, pelo menos em relação a um dos seguintes aspectos: estacionalidade (serem semideciduais), altitude (montanas) ou ripárias (associadas a cursos d'água). Tais florestas foram classificadas de acordo com o sistema de classificação do IBGE (Veloso et al. 1991, IBGE 1993). Adotou-se a modificação proposta por Oliveira-Filho et al. (1994d) de que o limite altitudinal entre as formações submontanas e montanas passasse de 500 para $750 \mathrm{~m}$. $\mathrm{Na}$ classificação, utilizou-se a localização das florestas e informações presentes nos artigos onde as listas foram publicadas.
Desta forma, consideraram-se nas análises os seguintes subgrupos de formação: floresta estacional semidecidual (formações montana e submontana), floresta ombrófila densa (formação montana) e florestas de galeria. Dentre estas florestas, as que ocorressem associadas a cursos d'água foram, também, consideradas ripárias, independente da classificação do IBGE.

As listas de espécies passaram por uma revisão dos epítetos específicos, para a verificação de sinônimos, com o auxílio do banco de dados de Oliveira-Filho \& Ratter (1994). Espécies arbustivas foram excluídas, por não serem consideradas em muitos levantamentos. As 24 áreas foram convertidas em uma matriz de presença/ausência, utilizada nas comparações florísticas. Utilizando-se o programa PC-ORD versão 3.0, compararam-se as 25 áreas (inclusive Camargos), através de uma análise de correspondência corrigida, ou DCA (Causton 1988). Optou-se pela DCA devido aos elevados autovalores ("eigenvalues") dos dois primeiros eixos (ver Resultados), indicando que uma razoável proporção da variação dos dados foi explicada (Kent \& Coker 1992). Os seguintes parâmetros fitossociológicos foram calculados para cada espécie, por meio do programa FITOPAC 2, de autoria de G.J. Shepherd, da Universidade Estadual de Campinas:

Tabela 1. Espécies arbustivas e arbóreas registradas na Mata de Camargos, município de Itutinga, MG. (162 espécies, 54 famílias). O número de coleta refere-se ao coletor EB (Eduardo van den Berg).

\begin{tabular}{|c|c|c|}
\hline Família/espécie & Nome vernacular & $\mathrm{N}^{\circ}$ de coleta \\
\hline \multicolumn{3}{|l|}{ ANACARDIACEAE } \\
\hline Lithraea molleoides (Vell.) Engler & aroeira-branca, aroeirinha & EB16 \\
\hline Tapirira guianensis Aublet & fruta-de-pombo, pombeiro & EB14 \\
\hline Tapirira obtusa (Benth.) Mitchell & pombeiro-branco, pau-pombo & EB12 \\
\hline \multicolumn{3}{|l|}{ ANNONACEAE } \\
\hline Annona cacans Warm. & araticum-cagão & EB117 \\
\hline Guatteria nigrescens Mart. & araticum-seco, pindaíba-preta & EB3, EB160 \\
\hline Rollinia laurifolia Schltdl. & araticum-bravo & EB2 \\
\hline Rollinia sylvatica Mart. & araticum-do-mato, cortiça & EB53 \\
\hline Xylopia brasiliensis Sprengel & pindaíba, pau-de-mastro & EB44 \\
\hline \multicolumn{3}{|l|}{ APOCYNACEAE } \\
\hline Aspidosperma cylindrocarpon Müll. Arg. & peroba-poca & EB60 \\
\hline Aspidosperma parvifolium A.DC. & guatambu, pereiro & EB151 \\
\hline Aspidosperma spruceanum Benth. & cabo-de-machado, peroba & EB59 \\
\hline \multicolumn{3}{|l|}{ AQUIFOLIACEAE } \\
\hline Ilex chamaedrifolia Reisseck & congonha & EB101 \\
\hline Ilex conocarpa Reisseck & catuaba-do-mato, congonha & EB67 \\
\hline \multicolumn{3}{|l|}{ ARALIACEAE } \\
\hline Dendropanax cuneatum (DC.) Decne \& Planchon & mandioca, maria-mole & EB25 \\
\hline Schefflera calva (Cham.) D.Frodin & mandiocão, morototó & EB56 \\
\hline \multicolumn{3}{|l|}{ ARECACEAE } \\
\hline Geonoma schottiana Mart. & guaricanga, aricanga & EB108 \\
\hline Syagrus flexuosa (Mart.) Becc. & coquinho-baboso & EB30 \\
\hline
\end{tabular}


(cont.)

\begin{tabular}{|c|c|c|}
\hline Família/espécie & Nome vernacular & $\mathrm{N}^{\circ}$ de coleta \\
\hline Syagrus romanzoffiana (Cham.) Glassman & jerivá, coco-baboso & EB111 \\
\hline \multicolumn{3}{|l|}{ ASTERACEAE } \\
\hline Baccharis lymanii G.M.Barroso & alecrim & EB110 \\
\hline Piptocarpha macropoda Baker & vassoura-preta & EB105 \\
\hline Vernonia diffusa Less. & vassourão-preto & EB158 \\
\hline Vernonia discolor Less. & vassourão-preto, cambará & EB143 \\
\hline \multicolumn{3}{|l|}{ BIGNONIACEAE } \\
\hline Jacaranda macrantha Cham. & caroba-do-mato & EB34 \\
\hline Tabebuia ochracea (Cham.) Rizz. & ipê-cascudo, piúna-do-campo & EB33 \\
\hline Tabebuia serratifolia (Vahl) Nichols & ipê-amarelo & EB115 \\
\hline \multicolumn{3}{|l|}{ BOMBACACEAE } \\
\hline Eriotheca candolleana (K.Schum.) A.Robyns. & pau-de-paina, catuaba-branca & EB95 \\
\hline \multicolumn{3}{|l|}{ BORAGINACEAE } \\
\hline Cordia ecalyculata Vell. & porangaba, café-de-bugre & EB31 \\
\hline Cordia rufescens A.DC. & mulato-branco, bago-de-boi & EB35 \\
\hline Cordia sellowiana Cham. & chá-de-bugre, juruté & EB32 \\
\hline \multicolumn{3}{|l|}{ BURSERACEAE } \\
\hline Protium heptaphyllum (Aublet) Marchand & breu-vermelho & EB107 \\
\hline Protium spruceanum (Benth.) Engler & almecega-de-casca-lisa, breu & EB43 \\
\hline Protium widgrenii Engler & almecega-cascuda & EB112 \\
\hline \multicolumn{3}{|l|}{ CAESALPINIACEAE } \\
\hline Copaifera langsdorffii Desf. & copaíba-vermelha, pau-d'óleo & EB13 \\
\hline \multicolumn{3}{|l|}{ CECROPIACEAE } \\
\hline Cecropia pachystachya Trécul & embaúba-cinzenta & EB142 \\
\hline \multicolumn{3}{|l|}{ CELASTRACEAE } \\
\hline Maytenus glazioviana Loesen & coração-de-bugre, cafezinho & EB141 \\
\hline \multicolumn{3}{|l|}{ CHRYSOBALANACEAE } \\
\hline Hirtella hebeclada Moric. & araçá-da-serra, azeitona & EB152 \\
\hline \multicolumn{3}{|l|}{ CLETHRACEAE } \\
\hline Clethra scabra Persoon & vermelhão, canjuja, vassourão & EB74, EB140 \\
\hline \multicolumn{3}{|l|}{ CLUSIACEAE } \\
\hline Calophyllum brasiliense Cambess. & guanandi, mangue & EB118 \\
\hline Garcinia gardneriana (Planchon \& Triana) Zappi & bacupari-miúdo, bacoparé & EB145 \\
\hline Kielmeyera lathrophyton Saddi & pau-santo & EB55 \\
\hline Tovomitopsis saldanhae Engler & azedinho, juruvoca & EB155 \\
\hline Vismia brasiliensis Choisy & pau-de-lacre, purga-de-vento & EB104 \\
\hline \multicolumn{3}{|l|}{ CUNONIACEAE } \\
\hline Lamanonia ternata Vell. & cedrilho & EB64 \\
\hline \multicolumn{3}{|l|}{ CYATHEACEAE } \\
\hline Nephelea sternbergii (Sternb.) Tryon & samambaiaçu-branco & EB49 \\
\hline Trichipteris phalerata (Mart.) Barr. & samambaiaçu & EB41 \\
\hline
\end{tabular}


(cont.)

\begin{tabular}{|c|c|c|}
\hline Família/espécie & Nome vernacular & $\mathrm{N}^{\circ}$ de coleta \\
\hline \multicolumn{3}{|l|}{ EBENACEAE } \\
\hline Diospyros hispida A.DC. & marmelada, olho-de-boi & EB57 \\
\hline \multicolumn{3}{|l|}{ ERYTHROXYLACEAE } \\
\hline *Erythroxylum cuneifolium (Mart) Schulz & fruta-de-pomba & EB135, EB134 \\
\hline *Erythroxylum deciduum A.St.-Hil. & fruta-de-pomba & EB47 \\
\hline \multicolumn{3}{|l|}{ EUPHORBIACEAE } \\
\hline Alchornea glandulosa Poepp. \& Endl & tapiá, tanheiro & EB138 \\
\hline Alchornea triplinervea (Sprengel) Müll.Arg. & tanheiro, tapiá-vermelho & EB136 \\
\hline Croton floribundus Sprengel & tapichingui, capichingui & EB137 \\
\hline *Croton lobatus $\mathrm{L}$. & Mandioquinha & EB106 \\
\hline Drypetes sessiliflora Fr.Allem. & folha-de-serra-grande & EB51 \\
\hline Hieronyma alchorneoides Fr.Allem. & licurana, uricurana & EB100 \\
\hline Hieronyma ferruginea Tul. & sangue-de-boi, quina-do-pará & EB63 \\
\hline Pera glabrata (Schtt.)Bailllon & pau-de sapateiro, cacho-de-arroz & EB10 \\
\hline *Phyllanthus claussenii Müll.Arg. & quebra-pedra-grande & EB54 \\
\hline Sapium glandulatum (Vell.) Pax & visgueiro, leiteiro & EB131 \\
\hline \multicolumn{3}{|l|}{ FABACEAE } \\
\hline Acosmium dasycarpum (Vogel) Yakovlev & sucupira-da-serra, chapada & EB19 \\
\hline Andira fraxinifolia Benth. & angelim-amargo, pau-de-morcego & EB77 \\
\hline Dalbergia miscolobium Benth & cabiúna-do-campo & EB50 \\
\hline Dalbergia villosa (Benth) Benth & milho-torrado & EB85 \\
\hline Machaerium hirtum (Vell.) Stellfeld & adolfo, jacarandá-de-espinho & EB88 \\
\hline Machaerium nictitans Benth. & jacarandá-ferro, bico-de-pato & EB94 \\
\hline Machaerium villosum Vogel & jacarandá-mineiro & EB149 \\
\hline Myrocarpus frondosus Fr.Allem. & cabreúva, óleo-pardo & EB70 \\
\hline Ormosia arborea (Vell.) Harms & tento, macanaíba & EB87 \\
\hline Platycyamus regnellii Benth. & pau-pereira, cataguá & EB153 \\
\hline Platypodium elegans Vogel & jacarandá-branco, faveiro & EB83 \\
\hline \multicolumn{3}{|l|}{ FLACOURTIACEAE } \\
\hline Casearia decandra Jacquin & canela-espeto, cambroé & EB123 \\
\hline Casearia gossypiosperma Briquet & japeiro, língua-de-tiú & EB127 \\
\hline Casearia lasiophylla Eichler & espeto-peludo & EB46 \\
\hline Casearia sylvestris Swartz & erva-de-lagarto, guaçatonga & EB68 \\
\hline Xylosma ciliatifolium (Clos.) Eichler & espinho-de-judeu & EB76 \\
\hline \multicolumn{3}{|l|}{ HIPPOCRATEACEAE } \\
\hline Salacia elliptica (Mart.) E.Don & bacupari & EB157 \\
\hline \multicolumn{3}{|l|}{ LACISTEMACEAE } \\
\hline Lacistema hasslerianum Chodat & cafeeiro-do-mato & EB65 \\
\hline
\end{tabular}


(cont.)

\begin{tabular}{|c|c|c|}
\hline Família/espécie & Nome vernacular & $\mathrm{N}^{\circ}$ de coleta \\
\hline \multicolumn{3}{|l|}{ LAMIACEAE } \\
\hline Hyptidendron asperrimum (Sprengel) Harley & salva-do-campo & EB45 \\
\hline \multicolumn{3}{|l|}{ LAURACEAE } \\
\hline Ocotea brachybotra (Meisner) Mez & canela-ameixa & EB66 \\
\hline Cryptocarya aschersoniana $\mathrm{Mez}$ & canela-branca, canela-de-jacu & EB129 \\
\hline Endlicheria paniculata (Sprengel) Macbr. & canela-peluda, canela-do-brejo & EB71 \\
\hline Licaria armeniaca (Nees) Kosterm. & canela-preta & EB58 \\
\hline Nectandra grandiflora Nees & canela-sassafrás & EB97 \\
\hline Nectandra nitidula Nees \& Mart. & canela-amarela & EB80 \\
\hline Nectandra oppositifolia Nees & canela-amarela, canela-ferrugem & EB124 \\
\hline Ocotea aciphylla Nees & canela-poca, canela-amarela & EB82 \\
\hline Ocotea acutifolia (Nees) Mez & canelinha-da-serra & EB163 \\
\hline Ocotea corymbosa (Meisner) Mez & canela-bosta, canela-preta & EB113 \\
\hline Ocotea diospyrifolia (Meisner) Mez & louro-amarelo & EB96 \\
\hline Ocotea odorifera (Vell.) Rohwer & canela-sassafrás, sassafrás & EB98 \\
\hline Ocotea pulchella (Nees) Mez & canela-prego, canelinha & EB103 \\
\hline \multicolumn{3}{|l|}{ MAGNOLIACEAE } \\
\hline Talauma ovata A.St.-Hil. & pinha-do-brejo, baguaçu & $\mathrm{EB} 21$ \\
\hline \multicolumn{3}{|l|}{ MALPIGHIACEAE } \\
\hline Heteropteris byrsonimifolia A.Juss. & folha-de-prata & EB11 \\
\hline \multicolumn{3}{|l|}{ MELASTOMATACEAE } \\
\hline *Leandra scabra DC. & pixirica, camará-do-mato & EB69 \\
\hline Miconia albicans Triana & canela-de-velho, olhos-de-porco & EB164 \\
\hline Miconia chartacea Triana & mexeriquinha & EB114 \\
\hline Miconia pepericarpa DC. & carvãozinho-vermelho & EB26 \\
\hline Miconia pusilliflora Triana & jacatirão & $\mathrm{EB} 84, \mathrm{~EB} 128$ \\
\hline Tibouchina candolleana (DC.) Cogn. & quaresma & EB166 \\
\hline Tibouchina stenocarpa (DC.) Cogn. & quaresmão, cuiupeva & EB148 \\
\hline \multicolumn{3}{|l|}{ MELIACEAE } \\
\hline Cabralea canjerana (Vell.) Mart. & cangerana, pindaiborana & EB22 \\
\hline Guarea macrophylla Vahl & cura-madre, marinheiro & EB132 \\
\hline Trichilia emarginata (Turcz.) C.DC. & catiguá, caá-tigoá & EB18 \\
\hline Trichilia pallida Swartz & catiguá & EB147 \\
\hline \multicolumn{3}{|l|}{ MEMECYLACEAE } \\
\hline Mouriri glazioviana Cogn. & mandapuçá & EB165 \\
\hline \multicolumn{3}{|l|}{ MIMOSACEAE } \\
\hline Inga vera Willd. & ingá-doce, ingá-miúdo & EB167 \\
\hline
\end{tabular}


(cont.)

\begin{tabular}{|c|c|c|}
\hline Família/espécie & Nome vernacular & $\mathrm{N}^{\circ}$ de coleta \\
\hline \multicolumn{3}{|l|}{ MONIMIACEAE } \\
\hline Mollinedia argyrogyna Perkins & congonha-branca & EB156 \\
\hline Mollinedia widgrenii A.DC. & pimenteira-brava & EB27 \\
\hline Siparuna apiosyce (Mart.) DC. & limoeiro-bravo, folha-santa & EB170 \\
\hline Siparuna guianensis Aublet & negramina, capitiú & EB4 \\
\hline \multicolumn{3}{|l|}{ MORACEAE } \\
\hline Naucleopsis mello-barretoi (Standl.) C.C.Berg & muiratinga & EB109 \\
\hline Sorocea bonplandii (Baillon) W.Burger & canxim, cincho & EB173 \\
\hline \multicolumn{3}{|l|}{ MYRSINACEAE } \\
\hline Myrsine coriacea (Swartz) R.Br. & pororoca-branca & EB168 \\
\hline Myrsine guianensis (Aublet) Kuntze & pororoca-cascuda & EB172 \\
\hline Myrsine lancifolia Mart. & pororoquinha-branca & EB7 \\
\hline Myrsine umbellata Mart. & pororoca-branca & EB78 \\
\hline Stylogyne ambigua (Mart.) Mez & pororoquinha-vermelha & EB169 \\
\hline \multicolumn{3}{|l|}{ MYRTACEAE } \\
\hline Calyptranthes brasiliensis Sprengel & guamirim & EB15 \\
\hline Calyptranthes clusiaefolia (Miq.) O.Berg & jaborandi & EB28 \\
\hline Calyptranthes lucida Mart. & jambo-do-mato, batinga-magra & EB17 \\
\hline Eugenia florida DC. & pimenteira & EB42 \\
\hline Eugenia pluriflora DC. & olho-de-boi & EB9 \\
\hline Gomidesia lindeniana O.Berg & guamirim-de-folha-grande & EB20 \\
\hline Myrcia multiflora (Lam.) DC. & cambuí & EB29 \\
\hline Myrcia tomentosa (Aublet) DC. & goiabão, goiabeira-brava & EB146 \\
\hline Myrcia velutina O.Berg & piúna, folha-miúda-cascuda & EB8 \\
\hline Myrcia venulosa DC. & guamirim-do-campo & EB36 \\
\hline Psidium cattleianum Sabine & araçá-do-mato & EB130 \\
\hline Psidium guineense Swartz & araçá-preto, araçá-perinha & EB37 \\
\hline Siphoneugena densiflora O.Berg & cravinho, piúna & EB99 \\
\hline Siphoneugena widgreniana (O.Berg) Burret & cravinho, lagoa-miúda & EB121 \\
\hline \multicolumn{3}{|l|}{ NYCTAGINACEAE } \\
\hline Guapira tomentosa (Casar.) Lundell & maria-mole, joão-mole & EB159 \\
\hline \multicolumn{3}{|l|}{ OCHNACEAE } \\
\hline Ouratea semiserrata (Mart. \& Nees) Engler & farinha-seca & EB119 \\
\hline \multicolumn{3}{|l|}{ OLEACEAE } \\
\hline Chionanthus arboreus (Eichler) P.S.Green & coxa-de-frango & EB89 \\
\hline \multicolumn{3}{|l|}{ PIPERACEAE } \\
\hline Piper arboreum Aublet & fruto-de-morcego, caapeba & EB177 \\
\hline Piper cernuит A.DC. & caapeba-de-orelha & EB154 \\
\hline
\end{tabular}


(cont.)

\begin{tabular}{|c|c|c|}
\hline Família/espécie & Nome vernacular & $\mathrm{N}^{\circ}$ de coleta \\
\hline *Piper gaudichaudianum Kunth & caapeba & EB75 \\
\hline \multicolumn{3}{|l|}{ PROTEACEAE } \\
\hline Euplassa incana (Klotzsch) Johnston & cabatã, catinga-de-barrão & EB73 \\
\hline Roupala brasiliensis Klotzsch & carne-de-vaca, catucaém & EB171 \\
\hline \multicolumn{3}{|l|}{ ROSACEAE } \\
\hline Prunus brasiliensis (Cham. \& Schltdl) D.Dietrich & pessegueiro-bravo & EB162 \\
\hline Prunus sellowii Koehne & pessegueiro-bravo & EB92 \\
\hline \multicolumn{3}{|l|}{ RUBIACEAE } \\
\hline Alibertia macrophylla K.Schum & marmelada-de-cachorro & EB6 \\
\hline *Alibertia sessilis (Vell) K.Schum & marmelinho-do-campo & EB38 \\
\hline Amaioua guianensis Aublet & marmelada, canela-de-veado & EB5 \\
\hline Faramea cyanea Müll.Arg. & cafezinho & EB79 \\
\hline Guettarda viburnioides (Cham.) Schltdl. & jangada, angélica & EB174 \\
\hline Ixora warmingii Müll.Arg. & ixora-do-mato & EB150 \\
\hline Psychotria deflexa DC. & pau-de-espeto, araçá-bravo & EB81 \\
\hline Randia nitida (Kunth) DC. & limão-bravo & EB1 \\
\hline Rudgea viburnioides (Cham.) Benth. & congonha-de-bugre & EB24 \\
\hline \multicolumn{3}{|l|}{ RUTACEAE } \\
\hline Esenbeckia febrifuga (A.St.-Hil.) A.Juss. & mamoninha, guaxupita & EB125 \\
\hline Galipea multiflora Schult. & guamixinga, grumarim & EB48 \\
\hline Zanthoxylum rhoifolium Lam. & mamica-de-porca & EB175 \\
\hline \multicolumn{3}{|l|}{ SAPINDACEAE } \\
\hline Cupania vernalis Cambess. & pau-de-cantil, gragoatã & EB39 \\
\hline \multicolumn{3}{|l|}{ STERCULIACEAE } \\
\hline Guazuma ulmifolia $\mathrm{L}$. & pau-de-motamba, camacã & EB90 \\
\hline \multicolumn{3}{|l|}{ STYRACACEAE } \\
\hline Styrax pohlii A.DC. & benjoeiro, salgueiro & EB180 \\
\hline \multicolumn{3}{|l|}{ SYMPLOCACEAE } \\
\hline Symplocos pubescens Klotzsch & sete-sangrias, saboeiro & EB176 \\
\hline \multicolumn{3}{|l|}{ THEACEAE } \\
\hline Ternstroemia alnifolia Wawra & pororoca-vermelha & EB178 \\
\hline \multicolumn{3}{|l|}{ THYMELAEACEAE } \\
\hline Daphnopsis fasciculata (Meisner) Nevl. & imbira-vermelha & EB91 \\
\hline \multicolumn{3}{|l|}{ VERBENACEAE } \\
\hline Aegiphila sellowiana Cham. & briaúva, pau-de-tamanco & EB179 \\
\hline Vitex polygama Cham. & maria-preta, velame-do-campo & EB40 \\
\hline \multicolumn{3}{|l|}{ VOCHYSIACEAE } \\
\hline Qualea jundiahy Warm. & pau-terra-da-mata & EB161 \\
\hline Vochysia tucanorum Mart. & pau-de-tucano, congonha-murici & EB133 \\
\hline
\end{tabular}

* Não fizeram parte das comparações florísticas com as outras 24 áreas, devido a serem, em geral, de porte arbustivo e, assim, não serem amostradas em muitos levantamentos. 
Tabela 2. Localização, tipo de formação vegetal, coordenadas geográficas, altitude, tipo climático, referências e número de espécies nas 25 áreas utilizadas nas análises florísticas (inclusive a Mata de Camargos, CM). O código (cód.) da área é o mesmo utilizado nas figuras 3-5. O tipo de formação vegetal segue o sistema de classificação do IBGE modificado (vide texto). FODM = Floresta ombrófila densa montana; FESS = Floresta estacional semidecidual sub-montana; FESM = Floresta estacional semidecidual montana; FG = Floresta de galeria. Quando, nos trabalhos consultados, as altitudes se apresentavam na forma de intervalo, foram utilizados os valores centrais. O tipo climático está de acordo com o sistema de classificação de Köppen. APA = Área de Proteção Ambiental; EE = Estação Ecológica; $\mathrm{PE}=$ Parque Estadual; $\mathrm{PM}=$ Parque Municipal; $\mathrm{PQ}=$ Parque Nacional; RB = Reserva Biológica; $\mathrm{RE}=$ Reserva Estadual; $\mathrm{RF}=$ Reserva Florestal.

\begin{tabular}{|c|c|c|c|c|c|c|c|c|}
\hline Cód. & Localização & Formação & Latitude & Longitude & Altitude & Clima & Referências & $\begin{array}{l}\text { No. } \\
\text { espécies }\end{array}$ \\
\hline AN & Anhembi - SP & FESS & $22^{\circ} 40^{\prime}$ & $48^{\circ} 10^{\prime}$ & 500 & $\mathrm{Cw}$ & $\begin{array}{l}\text { Cesar \& Leitão-Filho } \\
\text { 1990a,b }\end{array}$ & 127 \\
\hline $\mathrm{AT}$ & $\begin{array}{l}\text { PM Grota Funda, } \\
\text { Atibaia - SP }\end{array}$ & FODM & $23^{\circ} 10^{\prime}$ & $46^{\circ} 25^{\prime}$ & 1200 & $\mathrm{Cf}$ & $\begin{array}{l}\text { Meira-Neto et al. } \\
1989, \text { Grombone et al. } \\
1990\end{array}$ & 180 \\
\hline BA & RE Bauru - SP & FESS & $22^{\circ} 19^{\prime}$ & $49^{\circ} 04^{\prime}$ & 570 & $\mathrm{Cw}$ & Cavassan et al. 1984 & 58 \\
\hline BS & Bom Sucesso - MG & FESM* & $21^{\circ} 09^{\prime}$ & $44^{\circ} 54^{\prime}$ & 825 & $\mathrm{Cw}$ & $\begin{array}{l}\text { Oliveira-Filho et al. } \\
\text { 1994d }\end{array}$ & 222 \\
\hline $\mathrm{CM}$ & $\begin{array}{l}\text { Mata de Camargos, } \\
\text { Itutinga - MG }\end{array}$ & $\mathrm{FG}^{*}$ & $21^{\circ} 21^{\prime}$ & $44^{\circ} 37^{\prime}$ & 920 & $\mathrm{Cw}$ & Este trabalho & 154 \\
\hline CQ & Conquista - MG & FESS* & $19^{\circ} 59^{\prime}$ & $47^{\circ} 36^{\prime}$ & 515 & $\mathrm{Cw}$ & $\begin{array}{l}\text { Oliveira-Filho et al. } \\
1997\end{array}$ & 161 \\
\hline IP & $\begin{array}{l}\text { APA Corumbataí, } \\
\text { Ipeúna - SP }\end{array}$ & FESS* & $22^{\circ} 25^{\prime}$ & $48^{\circ} 45^{\prime}$ & 600 & $\mathrm{Cw}$ & $\begin{array}{l}\text { Mantovani et al. } \\
\text { 1986, Rodrigues } 1991\end{array}$ & 200 \\
\hline IT & Camargos, Itutinga - MG & $\mathrm{FG}^{*}$ & $21^{\circ} 22^{\prime}$ & $44^{\circ} 37^{\prime}$ & 917 & $\mathrm{Cw}$ & $\begin{array}{l}\text { Oliveira-Filho et al. } \\
\text { 1994d }\end{array}$ & 230 \\
\hline JA & UNESP Jabobicabal - SP & FESS & $21^{\circ} 15^{\prime}$ & $48^{\circ} 20^{\prime}$ & 560 & $\mathrm{Cw}$ & $\begin{array}{l}\text { Pinto 1989, } \\
\text { Marchiori et al. } 1992\end{array}$ & 83 \\
\hline $\mathrm{JU}$ & Serra do Japi, Jundiaí - SP & FODM & $23^{\circ} 11^{\prime}$ & $46^{\circ} 52^{\prime}$ & 1020 & $\mathrm{Cf}$ & $\begin{array}{l}\text { Rodrigues 1986, } \\
\text { Rodrigues et al. } 1989\end{array}$ & 174 \\
\hline LV & ESAL, Lavras - MG & FESM & $21^{\circ} 13^{\prime}$ & $45^{\circ} 00^{\prime}$ & 925 & $\mathrm{Cw}$ & $\begin{array}{l}\text { Oliveira-Filho et al. } \\
\text { 1994d }\end{array}$ & 171 \\
\hline $\mathrm{MD}$ & Madre de Deus de Minas - MG & FESM* & $21^{\circ} 29^{\prime}$ & $44^{\circ} 22^{\prime}$ & 925 & $\mathrm{Cw}$ & $\begin{array}{l}\text { Oliveira-Filho et al. } \\
\text { 1994d }\end{array}$ & 176 \\
\hline MG & RB Moji Guaçu - SP & FESS* & $22^{\circ} 16^{\prime}$ & $47^{\circ} 10^{\prime}$ & 535 & $\mathrm{Cw}$ & $\begin{array}{l}\text { Gibbs \& Leitão-Filho } \\
1978\end{array}$ & 147 \\
\hline $\mathrm{NP}$ & Serra da Cantareira - SP & FODM & $23^{\circ} 22^{\prime}$ & $46^{\circ} 26^{\prime}$ & 1025 & $\mathrm{Cf}$ & Baitello et al. 1992 & 109 \\
\hline PB & $\begin{array}{l}\text { RB Poço Bonito, } \\
\text { Lavras - MG }\end{array}$ & FESM* & $21^{\circ} 20^{\prime}$ & $45^{\circ} 00^{\prime}$ & 1150 & $\mathrm{Cw}$ & $\begin{array}{l}\text { Oliveira-Filho et al. } \\
\text { 1994d }\end{array}$ & 199 \\
\hline $\mathrm{PF}$ & RE Porto Ferreira - SP & FESS* & $21^{\circ} 49^{\prime}$ & $47^{\circ} 25^{\prime}$ & 580 & $\mathrm{Cw}$ & $\begin{array}{l}\text { Bertoni \& Martins } \\
1987\end{array}$ & 146 \\
\hline PQ & PE S. Rita Passa Quatro - SP & FESS & $21^{\circ} 40^{\prime}$ & $47^{\circ} 38^{\prime}$ & 630 & $\mathrm{Cw}$ & $\begin{array}{l}\text { Bertoni et al. } \\
\text { 1988, Martins } 1991\end{array}$ & 110 \\
\hline PR & Paracatu - MG & $\mathrm{FG}^{*}$ & $17^{\circ} 10^{\prime}$ & $46^{\circ} 57^{\prime}$ & 900 & Aw & Felfili 1990, 1994 & 64 \\
\hline PT & Patrocínio - MG & $\mathrm{FG}^{*}$ & $19^{\circ} 20^{\prime}$ & $46^{\circ} 47^{\prime}$ & 950 & Aw & Felfili 1990, 1994 & 96 \\
\hline $\mathrm{RC}$ & Rio Claro - SP & FESS & $22^{\circ} 22^{\prime}$ & $47^{\circ} 28^{\prime}$ & 630 & $\mathrm{Cw}$ & $\begin{array}{l}\text { Pagano \& Leitão-Filho } \\
1987\end{array}$ & 156 \\
\hline $\mathrm{SC}$ & PN da Serra da Canastra - MG & $\mathrm{FG}^{*}$ & $20^{\circ} 30^{\prime}$ & $46^{\circ} 30^{\prime}$ & 950 & $\mathrm{Aw} / \mathrm{Cw}$ & Mota 1984 & 97 \\
\hline SJ & RF S. José dos Campos - SP & FODM & $23^{\circ} 05^{\prime}$ & $45^{\circ} 55^{\prime}$ & 840 & $\mathrm{Cf}$ & Silva 1989 & 167 \\
\hline
\end{tabular}


(cont.)

\begin{tabular}{|c|c|c|c|c|c|c|c|c|}
\hline Cód. & Localização & Formação & Latitude & Longitude & Altitude & Clima & Referências & $\begin{array}{l}\text { No. } \\
\text { espécies }\end{array}$ \\
\hline $\mathrm{TD}$ & Serra S. José, Tiradentes - MG & FESM & $21^{\circ} 01^{\prime}$ & $44^{\circ} 14^{\prime}$ & 900 & $\mathrm{Cw}$ & $\begin{array}{l}\text { Oliveira-Filho et al. } \\
\text { 1994d }\end{array}$ & 257 \\
\hline TS & PE Teodoro Sampaio - SP & FESS* & $22^{\circ} 30^{\prime}$ & $52^{\circ} 20^{\prime}$ & 300 & $\mathrm{Cw}$ & $\begin{array}{l}\text { Campos \& } \\
\text { Heinsdijk1970, Baitello } \\
\text { et al. } 1988\end{array}$ & 123 \\
\hline UB & EE Panga, Uberlândia - MG & $\mathrm{FG}^{*}$ & $19^{\circ} 10^{\prime}$ & $48^{\circ} 24^{\prime}$ & 800 & Aw & Schiavini 1992 & 96 \\
\hline
\end{tabular}

* Formação ripária

densidade absoluta (DA), freqüência absoluta (FA) e dominância absoluta (DoA), baseada na área basal à altura do solo, bem como seus respectivos parâmetros relativos (Mueller-Dombois e Ellenberg 1974). A partir dos parâmetros relativos, calculou-se o valor de importância (VI) para cada espécie. Foram calculados, também, o índice de diversidade de espécies de Shannon-Wiener ( $\left.H^{\prime}\right)$ e o índice de equabilidade de Pielou (J') (Brower e Zar 1984). Para comparar a estrutura fitossociológica da mata de Camargos com outras quatro áreas da bacia do rio Grande-Poço Bonito (PB, Oliveira-Filho et al. 1994a), Bom Sucesso/Macaia (BS, Carvalho et al. 1995), Itutinga (IT, Oliveira-Filho et al. 1994c) e Madre de Deus de Minas (MD, Oliveira-Filho et al. 1994e) - foi construída uma matriz de valores de distância euclidiana (Gauch 1982), calculados entre as cinco áreas (incluindo Camargos), usando o VI de cada espécie. A partir dos valores de distância euclidiana, construiu-se um dendrograma usando o método de pareamento por média aritmética simples (UPGMA - Gauch 1982). Os índices

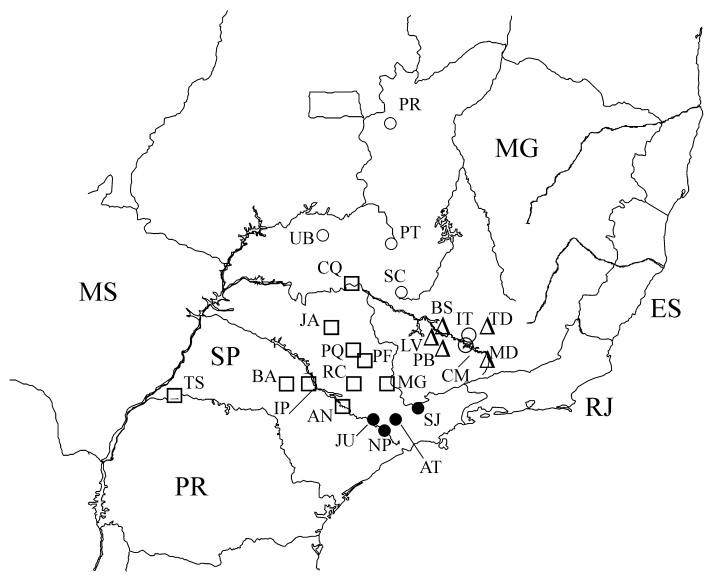

Figura 3. Mapa da região sudeste do Brasil mostrando a localização das 25 áreas utilizadas nas análises florísticas. As áreas de floresta estão classificadas de acordo com o sistema do IBGE modificado (Oliveira-Filho 1994d) e são identificadas pelos códigos de duas letras da tabela 2. Floresta ombrófila densa montana (•); Floresta estacional semidecidual submontana ( $\square$ ); Floresta estacional semidecidual montana $(\Delta)$; Floresta de galeria (O). de diversidade ( $\left.\mathrm{H}^{\prime}\right)$ das quatro áreas foram comparados com Camargos pelo teste de $\mathrm{t}$ (Hutcheson 1970 apud Zar 1984).

\section{Resultados}

Levantamento florístico - No total, foram registradas 162 espécies arbóreas e arbustivas pertencentes a 54 famílias (tabela 1). Entre os indivíduos amostrados apenas nas parcelas, foram encontradas 141 espécies e 52 famílias. As famílias com maior número de espécies no levantamento total foram Myrtaceae (14), Lauraceae (13), Fabaceae (11), Euphorbiaceae (10), Rubiaceae (nove), Melastomataceae (oito) e Annonaceae, Clusiaceae, Flacourtiaceae e Myrsinaceae, com cinco cada uma. As leguminosas como um todo (Fabaceae, Mimosaceae e Caesalpiniaceae) somaram 13 espécies.

A análise de correspondência corrigida DCA (figura 4) apresentou autovalores ("eigenvalues") elevados para os dois primeiros eixos $(0,493$, para o primeiro eixo e 0,391 , para o segundo). Os dois primeiros eixos da DCA sintetizaram cerca de $88 \%$ da variação dos dados. Quase $50 \%$ desta variação foram sintetizados pelo primeiro eixo, que separou as florestas ombrófilas densas montanas das demais fisionomias. O segundo eixo da DCA separou, de um lado, as florestas estacionais semideciduais submontanas e, de outro, as florestas estacionais semideciduais montanas, próximas às florestas de galeria. As florestas ombrófilas densas montanas foram colocadas numa posição intermediária entre esses extremos.

A DCA separou claramente as florestas ombrófilas densas montanas e florestas estacionais semideciduais submontanas das outras duas fisionomias. As florestas estacionais semideciduais montanas, todas da região do alto rio Grande, e as florestas de galeria 


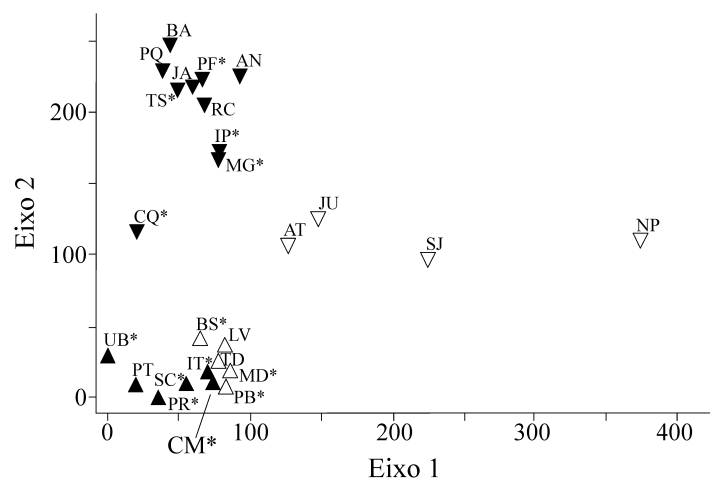

Figura 4. Resultados gráficos dos dois primeiros eixos da DCA (análise de correspondência corrigida) para as 25 áreas comparadas (incluindo Camargos). Os eixos correspondem aos autovalores. Os códigos das áreas são os mesmos apresentados na tabela 2. Asteriscos (*) marcam as áreas de florestas ripárias. Floresta estacional semidecidual montana $(\Delta)$; Floresta de galeria $(\boldsymbol{\Delta})$; Floresta ombrófila densa montana $(\nabla)$; Floresta estacional semidecidual submontana $(\boldsymbol{\nabla})$.

apresentaram-se quase como um grupo único. Dentre as fisionomias, a que apresentou um grupo menos coeso foi a das florestas ombrófilas densas montanas. Nos grupos das florestas estacionais semideciduais submontanas e florestas de galeria, Conquista (CQ) e Uberlândia (UB), apresentaram-se como as áreas mais distintas dos seus respectivos grupos. As florestas da região do alto rio Grande (florestas estacionais semideciduais montanas de Bom Sucesso, Madre de Deus e Poço Bonito e florestas de galeria de Camargos e Itutinga) formaram um grupo muito coeso, independente da fisionomia ou associação a cursos d'água (florestas ripárias). As áreas de florestas ripárias e não ripárias existentes tanto na fisionomia floresta estacional semidecidual montana como entre as florestas estacionais semideciduais submontanas apresentaram-se misturadas entre si, sem qualquer padrão aparente (figura 4).

Levantamento fitossociológico - Foram amostrados nas parcelas $(0,84$ ha) 2145 indivíduos com DAS $\geq 5 \mathrm{~cm}$, distribuídos em 141 espécies (tabela 3) e 51 famílias, resultando em uma densidade estimada de 2553,57 indivíduos.ha- ${ }^{-1}$. A área basal estimada foi de $45,03 \mathrm{~m}^{2} \cdot \mathrm{ha}^{-1}$. A altura média foi de $7,78 \mathrm{~m}$, sendo a máxima de $20 \mathrm{~m}$ e a mínima $0,5 \mathrm{~m}$. O diâmetro médio foi de $12,23 \mathrm{~cm}$, o máximo de $66,21 \mathrm{~cm}$ e o mínimo de $5 \mathrm{~cm}$. O índice de diversidade Shannon-
Wiener resultou no valor de 3,924 nats.indivíduo ${ }^{-1} \mathrm{e}$ o índice de equabilidade de Pielou, em 0,793. As espécies com maior VI foram Protium spruceanum, Copaifera langsdorffii, Pera glabrata, Ixora warmingii, Trichilia emarginata, Naucleopsis mello-barretoi, Protium widgrenii, Ocotea odorifera, Vochysia tucanorum e Alibertia macrophylla. Estas 10 espécies alcançaram 42,9\% da soma do VI de todas as espécies.

O índice de diversidade Shannon-Wiener para Camargos foi semelhante ao de Itutinga, maior que o de Madre de Deus e inferior aos do Poço Bonito e Bom Sucesso (tabela 4). A figura 5 apresenta um dendrograma de classificação hierárquica das cinco áreas comparadas. Formaram-se dois grupos distintos. O primeiro foi composto por Camargos (CM), Itutinga (IT) e Bom Sucesso (BS). Dentro deste grupo, as áreas mais semelhantes entre si foram Camargos e Itutinga. $\mathrm{O}$ outro grupo foi formado por Madre de Deus (MD) e Poço Bonito (PB).

\section{Discussão}

Levantamento florístico - As maiores semelhanças florísticas apresentadas entre Camargos e demais florestas da bacia do alto rio Grande poderiam ser explicadas pelo fato de ocorrerem em uma mesma região, com altitudes e macroclimas semelhantes, apresentando todas elas, durante a estação seca, deciduidade de 20 a $50 \%$ dos indivíduos. Embora Camargos (CM) e Itutinga (IT) tivessem sido classificadas como florestas de galeria, suas floras foram muito semelhantes às das demais florestas do alto rio Grande (PB, BS e MD), que são florestas estacionais semideciduais montanas. Aparentemente, as florestas de galeria existentes na região do alto rio Grande seriam penetrações das florestas estacionais semideciduais montanas na disjunção da região fitoecológica das savanas, que ocorre na altura do reservatório de Camargos (ver Material e Métodos - Classificação da vegetação). Oliveira-Filho et al. (1994d) salientaram que as florestas de galeria na região do cerrado de Minas Gerais têm alta similaridade florística com as florestas estudadas na região do alto rio Grande, devido tanto ao clima (fortemente estacional) quanto à altitude ( $>700 \mathrm{~m})$.

É possível que outros fatores, como altitude e clima semelhantes, e talvez a proximidade geográ- 
Tabela 3. Espécies de árvores com DAS $\geq 5 \mathrm{~cm}$ amostradas em 28 parcelas de 10 x $30 \mathrm{~m}$ (área total: 0,84 ha) na Mata de Camargos, município de Itutinga, Minas Gerais, com seus respectivos parâmetros fitossociológicos. $\mathrm{N}=$ número de indivíduos; $\mathrm{P}=$ número de parcelas onde ocorre; $\mathrm{AB}=$ área basal; $\mathrm{d}=$ diâmetro médio; $\mathrm{h}=$ altura média; $\mathrm{DA}=$ densidade absoluta (indivíduos/ha); $\mathrm{FA}=$ frequiência absoluta; $\mathrm{DoA}=$ dominância absoluta; $\mathrm{DR}=$ densidade relativa; $\mathrm{FR}=$ frequiência relativa; DoR = dominância relativa; $\mathrm{VI}=$ valor de importância $(\%)$

\begin{tabular}{|c|c|c|c|c|c|c|c|c|c|c|c|c|}
\hline Espécie & $\begin{array}{c}\mathrm{N} \\
\left(\mathrm{m}^{2}\right) \\
\end{array}$ & $\mathrm{P}$ & $\begin{array}{r}\mathrm{AB} \\
\left(\mathrm{m}^{2}\right) \\
\end{array}$ & $\begin{array}{c}\mathrm{D} \\
(\mathrm{cm}) \\
\end{array}$ & $\begin{array}{c}\mathrm{h} \\
(\mathrm{m}) \\
\end{array}$ & $\begin{array}{c}\text { DA } \\
(1 / \mathrm{ha}) \\
\end{array}$ & $\begin{array}{l}\text { FA } \\
(\%) \\
\end{array}$ & $\begin{array}{c}\text { DoA } \\
\left(\mathrm{m}^{2} / \mathrm{ha}\right) \\
\end{array}$ & $\begin{array}{l}\text { DR } \\
(\%) \\
\end{array}$ & $\begin{array}{l}\text { FR } \\
(\%) \\
\end{array}$ & $\begin{array}{l}\text { DoR } \\
(\%) \\
\end{array}$ & VI \\
\hline Protium spruceanum & 249 & 28 & 5,386 & 14,4 & 9,9 & 296,4 & 100,0 & 6,412 & 11,61 & 3,49 & 14,24 & 29,34 \\
\hline Copaifera langsdorffii & 180 & 27 & 6,576 & 17,4 & 10,2 & 214,3 & 96,4 & 7,829 & 8,39 & 3,36 & 17,39 & 29,14 \\
\hline Pera obovata & 146 & 24 & 3,716 & 15,4 & 9,9 & 173,8 & 85,7 & 4,423 & 6,81 & 2,99 & 9,82 & 19,62 \\
\hline Ixora warmingii & 118 & 27 & 1,132 & 10,2 & 6,9 & 140,5 & 96,4 & 1,348 & 5,50 & 3,36 & 2,99 & 11,86 \\
\hline Trichilia emarginata & 76 & 18 & 0,500 & 8,4 & 6,9 & 90,5 & 64,3 & 0,595 & 3,54 & 2,24 & 1,32 & 7,11 \\
\hline Naucleopsis mello-barretoi & 61 & 18 & 0,722 & 10,9 & 7,9 & 72,6 & 64,3 & 0,859 & 2,84 & 2,24 & 1,91 & 6,99 \\
\hline Protium widgrenii & 56 & 18 & 0,630 & 10,3 & 7,4 & 66,7 & 64,3 & 0,750 & 2,61 & 2,24 & 1,67 & 6,52 \\
\hline Ocotea odorifera & 56 & 12 & 0,819 & 11,9 & 7,6 & 66,7 & 42,9 & 0,975 & 2,61 & 1,49 & 2,16 & 6,27 \\
\hline Vochysia tucanorum & 65 & 8 & 0,845 & 11,4 & 5,3 & 77,4 & 28,6 & 1,006 & 3,03 & 1,00 & 2,23 & 6,26 \\
\hline Alibertia macrophylla & 47 & 14 & 0,668 & 12,3 & 7,3 & 56,0 & 50,0 & 0,796 & 2,19 & 1,74 & 1,77 & 5,70 \\
\hline Amaioua guianensis & 44 & 21 & 0,385 & 9,6 & 7,1 & 52,4 & 75,0 & 0,458 & 2,05 & 2,62 & 1,02 & 5,68 \\
\hline Xylopia brasiliensis & 30 & 14 & 0,911 & 16,9 & 12,3 & 35,7 & 50,0 & 1,085 & 1,40 & 1,74 & 2,41 & 5,55 \\
\hline Ocotea corymbosa & 33 & 20 & 0,491 & 11,9 & 9,6 & 39,3 & 71,4 & 0,585 & 1,54 & 2,49 & 1,30 & 5,33 \\
\hline Tapirira obtusa & 30 & 15 & 0,758 & 14,4 & 8,4 & 35,7 & 53,6 & 0,902 & 1,40 & 1,87 & 2,00 & 5,27 \\
\hline Dendropanax cuneatum & 35 & 18 & 0,266 & 8,9 & 6,1 & 41,7 & 64,3 & 0,316 & 1,63 & 2,24 & 0,70 & 4,58 \\
\hline Tapirira guianensis & 39 & 12 & 0,462 & 10,8 & 7,7 & 46,4 & 42,9 & 0,550 & 1,82 & 1,49 & 1,22 & 4,53 \\
\hline Geonoma schottiana & 48 & 15 & 0,138 & 6,0 & 3,9 & 57,1 & 53,6 & 0,164 & 2,24 & 1,87 & 0,36 & 4,47 \\
\hline Calophyllum brasiliense & 36 & 14 & 0,371 & 10,3 & 8,0 & 42,9 & 50,0 & 0,442 & 1,68 & 1,74 & 0,98 & 4,40 \\
\hline Hieronyma ferruginea & 24 & 17 & 0,420 & 12,8 & 8,5 & 28,6 & 60,7 & 0,500 & 1,12 & 2,12 & 1,11 & 4,35 \\
\hline Cabralea canjerana & 21 & 9 & 0,800 & 14,7 & 7,1 & 25,0 & 32,1 & 0,952 & 0,98 & 1,12 & 2,11 & 4,21 \\
\hline Myrsine umbellata & 39 & 10 & 0,262 & 8,7 & 5,9 & 46,4 & 35,7 & 0,312 & 1,82 & 1,25 & 0,69 & 3,76 \\
\hline Casearia sylvestris & 35 & 13 & 0,164 & 7,3 & 5,8 & 41,7 & 46,4 & 0,195 & 1,63 & 1,62 & 0,43 & 3,68 \\
\hline
\end{tabular}


(cont.)

\begin{tabular}{|c|c|c|c|c|c|c|c|c|c|c|c|c|}
\hline Espécie & $\begin{array}{c}\mathrm{N} \\
\left(\mathrm{m}^{2}\right) \\
\end{array}$ & $\mathrm{P}$ & $\begin{array}{r}\mathrm{AB} \\
\left(\mathrm{m}^{2}\right) \\
\end{array}$ & $\begin{array}{c}\mathrm{D} \\
(\mathrm{cm}) \\
\end{array}$ & $\begin{array}{c}\mathrm{h} \\
(\mathrm{m}) \\
\end{array}$ & $\begin{array}{c}\text { DA } \\
(1 / \mathrm{ha}) \\
\end{array}$ & $\begin{array}{l}\text { FA } \\
(\%) \\
\end{array}$ & $\begin{array}{c}\text { DoA } \\
\left(\mathrm{m}^{2} / \mathrm{ha}\right)\end{array}$ & $\begin{array}{l}\text { DR } \\
(\%) \\
\end{array}$ & $\begin{array}{l}\text { FR } \\
(\%) \\
\end{array}$ & $\begin{array}{l}\text { DoR } \\
(\%) \\
\end{array}$ & $\mathrm{VI}$ \\
\hline Trichipteris phalerata & 32 & 8 & 0,442 & 12,7 & 3,2 & 38,1 & 28,6 & 0,526 & 1,49 & 1,00 & 1,17 & 3,66 \\
\hline Guarea macrophylla & 21 & 15 & 0,301 & 10,5 & 6,0 & 25,0 & 53,6 & 0,358 & 0,98 & 1,87 & 0,80 & 3,64 \\
\hline Ocotea diospyrifolia & 8 & 7 & 0,795 & 30,8 & 12,9 & 9,5 & 25,0 & 0,947 & 0,37 & 0,87 & 2,10 & 3,35 \\
\hline Annona cacans & 8 & 6 & 0,820 & 34,4 & 15,0 & 9,5 & 21,4 & 0,976 & 0,37 & 0,75 & 2,17 & 3,29 \\
\hline Andira fraxinifolia & 29 & 11 & 0,191 & 8,5 & 4,9 & 34,5 & 39,3 & 0,227 & 1,35 & 1,37 & 0,50 & 3,23 \\
\hline Myrcia venulosa & 22 & 10 & 0,245 & 10,9 & 6,2 & 26,2 & 35,7 & 0,291 & 1,03 & 1,25 & 0,65 & 2,92 \\
\hline Calyptranthes lucida & 15 & 12 & 0,251 & 11,2 & 6,3 & 17,9 & 42,9 & 0,299 & 0,70 & 1,49 & 0,66 & 2,86 \\
\hline Mollinedia argyrogyna & 17 & 12 & 0,164 & 10,2 & 5,2 & 20,2 & 42,9 & 0,196 & 0,79 & 1,49 & 0,43 & 2,72 \\
\hline Clethra scabra & 16 & 9 & 0,305 & 13,7 & 7,4 & 19,0 & 32,1 & 0,363 & 0,75 & 1,12 & 0,81 & 2,67 \\
\hline Machaerium nictitans & 7 & 6 & 0,546 & 26,9 & 12,7 & 8,3 & 21,4 & 0,650 & 0,33 & 0,75 & 1,44 & 2,52 \\
\hline Siparuna guianensis & 15 & 12 & 0,073 & 7,1 & 6,2 & 17,9 & 42,9 & 0,087 & 0,70 & 1,49 & 0,19 & 2,39 \\
\hline Calyptranthes clusiaefolia & 17 & 11 & 0,075 & 7,1 & 6,1 & 20,2 & 39,3 & 0,089 & 0,79 & 1,37 & 0,20 & 2,36 \\
\hline Myrcia velutina & 22 & 8 & 0,126 & 8,1 & 4,5 & 26,2 & 28,6 & 0,150 & 1,03 & 1,00 & 0,33 & 2,35 \\
\hline Casearia decandra & 18 & 10 & 0,077 & 7,2 & 6,3 & 21,4 & 35,7 & 0,092 & 0,84 & 1,25 & 0,20 & 2,29 \\
\hline Jacaranda macrantha & 7 & 5 & 0,503 & 20,8 & 7,9 & 8,3 & 17,9 & 0,598 & 0,33 & 0,62 & 1,33 & 2,28 \\
\hline Machaerium villosum & 5 & 5 & 0,480 & 29,1 & 11,5 & 6,0 & 17,9 & 0,571 & 0,23 & 0,62 & 1,27 & 2,12 \\
\hline Rollinia laurifolia & 14 & 8 & 0,171 & 11,4 & 7,3 & 16,7 & 28,6 & 0,203 & 0,65 & 1,00 & 0,45 & 2,10 \\
\hline Lacistema hasslerianum & 15 & 10 & 0,041 & 5,9 & 4,3 & 17,9 & 35,7 & 0,049 & 0,70 & 1,25 & 0,11 & 2,05 \\
\hline Guazuma ulmifolia & 11 & 10 & 0,107 & 10,3 & 8,2 & 13,1 & 35,7 & 0,128 & 0,51 & 1,25 & 0,28 & 2,04 \\
\hline Ocotea aciphylla & 11 & 7 & 0,231 & 14,6 & 7,2 & 13,1 & 25,0 & 0,275 & 0,51 & 0,87 & 0,61 & 2,00 \\
\hline Alchornea glandulosa & 8 & 7 & 0,239 & 17,3 & 10,5 & 9,5 & 25,0 & 0,284 & 0,37 & 0,87 & 0,63 & 1,88 \\
\hline Myrsine guianensis & 26 & 2 & 0,119 & 7,2 & 5,0 & 31,0 & 7,1 & 0,141 & 1,21 & 0,25 & 0,31 & 1,77 \\
\hline Talauma ovata & 11 & 5 & 0,229 & 15,3 & 9,2 & 13,1 & 17,9 & 0,273 & 0,51 & 0,62 & 0,61 & 1,74 \\
\hline
\end{tabular}


(cont.)

\begin{tabular}{|c|c|c|c|c|c|c|c|c|c|c|c|c|}
\hline Espécie & $\begin{array}{c}\mathrm{N} \\
\left(\mathrm{m}^{2}\right)\end{array}$ & $\mathrm{P}$ & $\begin{array}{l}\mathrm{AB} \\
\left(\mathrm{m}^{2}\right) \\
\end{array}$ & $\begin{array}{c}\mathrm{D} \\
(\mathrm{cm}) \\
\end{array}$ & $\begin{array}{c}\mathrm{h} \\
(\mathrm{m}) \\
\end{array}$ & $\begin{array}{c}\text { DA } \\
(1 / \mathrm{ha}) \\
\end{array}$ & $\begin{array}{l}\text { FA } \\
(\%) \\
\end{array}$ & $\begin{array}{c}\text { DoA } \\
\left(\mathrm{m}^{2} / \mathrm{ha}\right)\end{array}$ & $\begin{array}{l}\mathrm{DR} \\
(\%) \\
\end{array}$ & $\begin{array}{l}\text { FR } \\
(\%) \\
\end{array}$ & $\begin{array}{c}\text { DoR } \\
(\%) \\
\end{array}$ & VI \\
\hline Vitex polygama & 6 & 5 & 0,308 & 16,8 & 7,6 & 7,1 & 17,9 & 0,367 & 0,28 & 0,62 & 0,81 & 1,72 \\
\hline Mollinedia widgrenii & 9 & 8 & 0,107 & 10,1 & 6,8 & 10,7 & 28,6 & 0,127 & 0,42 & 1,00 & 0,28 & 1,70 \\
\hline Tovomitopsis saldanhae & 6 & 2 & 0,373 & 23,1 & 10,8 & 7,1 & 7,1 & 0,444 & 0,28 & 0,25 & 0,99 & 1,52 \\
\hline Calyptranthes brasiliensis & 10 & 7 & 0,050 & 7,7 & 6,0 & 11,9 & 25,0 & 0,060 & 0,47 & 0,87 & 0,13 & 1,47 \\
\hline Vismia brasiliensis & 8 & 6 & 0,113 & 12,2 & 9,0 & 9,5 & 21,4 & 0,134 & 0,37 & 0,75 & 0,30 & 1,42 \\
\hline Protium heptaphyllum & 7 & 7 & 0,069 & 10,3 & 6,5 & 8,3 & 25,0 & 0,082 & 0,33 & 0,87 & 0,18 & 1,38 \\
\hline Platycyamus regnellii & 8 & 3 & 0,223 & 14,8 & 8,6 & 9,5 & 10,7 & 0,266 & 0,37 & 0,37 & 0,59 & 1,34 \\
\hline Vernonia diffusa & 11 & 3 & 0,168 & 12,3 & 4,0 & 13,1 & 10,7 & 0,199 & 0,51 & 0,37 & 0,44 & 1,33 \\
\hline Ocotea pulchella & 7 & 5 & 0,134 & 15,1 & 7,0 & 8,3 & 17,9 & 0,159 & 0,33 & 0,62 & 0,35 & 1,30 \\
\hline Aspidosperma spruceanum & 7 & 3 & 0,223 & 17,7 & 10,4 & 8,3 & 10,7 & 0,265 & 0,33 & 0,37 & 0,59 & 1,29 \\
\hline Myrcia tomentosa & 7 & 6 & 0,041 & 8,1 & 6,1 & 8,3 & 21,4 & 0,049 & 0,33 & 0,75 & 0,11 & 1,18 \\
\hline Schefflera calva & 6 & 6 & 0,041 & 8,5 & 9,3 & 7,1 & 21,4 & 0,049 & 0,28 & 0,75 & 0,11 & 1,13 \\
\hline Trichilia pallida & 6 & 6 & 0,037 & 8,4 & 5,6 & 7,1 & 21,4 & 0,044 & 0,28 & 0,75 & 0,10 & 1,13 \\
\hline Erythroxylum deciduum & 8 & 5 & 0,041 & 7,8 & 3,0 & 9,5 & 17,9 & 0,049 & 0,37 & 0,62 & 0,11 & 1,10 \\
\hline Alchornea triplinervea & 5 & 4 & 0,133 & 14,9 & 9,0 & 6,0 & 14,3 & 0,159 & 0,23 & 0,50 & 0,35 & 1,08 \\
\hline Nectandra oppositifolia & 5 & 5 & 0,084 & 12,9 & 8,8 & 6,0 & 17,9 & 0,100 & 0,23 & 0,62 & 0,22 & 1,08 \\
\hline Casearia lasiophylla & 6 & 5 & 0,053 & 9,9 & 7,0 & 7,1 & 17,9 & 0,064 & 0,28 & 0,62 & 0,14 & 1,04 \\
\hline Guatteria nigrescens & 6 & 5 & 0,045 & 9,4 & 8,1 & 7,1 & 17,9 & 0,054 & 0,28 & 0,62 & 0,12 & 1,02 \\
\hline Casearia gossypiosperma & 6 & 5 & 0,019 & 6,2 & 5,5 & 7,1 & 17,9 & 0,022 & 0,28 & 0,62 & 0,05 & 0,95 \\
\hline Faramea cyanea & 5 & 4 & 0,077 & 13,5 & 8,5 & 6,0 & 14,3 & 0,092 & 0,23 & 0,50 & 0,20 & 0,94 \\
\hline Cordia sellowiana & 3 & 2 & 0,196 & 27,9 & 16,0 & 3,6 & 7,1 & 0,233 & 0,14 & 0,25 & 0,52 & 0,91 \\
\hline Rudgea viburnioides & 7 & 4 & 0,029 & 7,0 & 3,2 & 8,3 & 14,3 & 0,034 & 0,33 & 0,50 & 0,08 & 0,90 \\
\hline Cryptocarya aschersoniana & 3 & 1 & 0,223 & 24,5 & 10,8 & 3,6 & 3,6 & 0,266 & 0,14 & 0,12 & 0,59 & 0,85 \\
\hline
\end{tabular}


(cont.)

\begin{tabular}{|c|c|c|c|c|c|c|c|c|c|c|c|c|}
\hline Espécie & $\begin{array}{r}\mathrm{N} \\
\left(\mathrm{m}^{2}\right) \\
\end{array}$ & $\mathrm{P}$ & $\begin{array}{c}\mathrm{AB} \\
\left(\mathrm{m}^{2}\right)\end{array}$ & $\begin{array}{c}\mathrm{D} \\
(\mathrm{cm}) \\
\end{array}$ & $\begin{array}{c}\mathrm{h} \\
(\mathrm{m}) \\
\end{array}$ & $\begin{array}{c}\text { DA } \\
(1 / \mathrm{ha}) \\
\end{array}$ & $\begin{array}{l}\text { FA } \\
(\%) \\
\end{array}$ & $\begin{array}{c}\text { DoA } \\
\left(\mathrm{m}^{2} / \mathrm{ha}\right) \\
\end{array}$ & $\begin{array}{l}\mathrm{DR} \\
(\%) \\
\end{array}$ & $\begin{array}{l}\text { FR } \\
(\%) \\
\end{array}$ & $\begin{array}{c}\text { DoR } \\
(\%) \\
\end{array}$ & VI \\
\hline Esenbeckia febrifuga & 9 & 3 & 0,023 & 5,7 & 5,2 & 10,7 & 10,7 & 0,027 & 0,42 & 0,37 & 0,06 & 0,85 \\
\hline Gomidesia lindeniana & 6 & 4 & 0,023 & 6,8 & 4,5 & 7,1 & 14,3 & 0,027 & 0,28 & 0,50 & 0,06 & 0,84 \\
\hline Siphoneugena widgreniana & 5 & 4 & 0,040 & 9,4 & 6,4 & 6,0 & 14,3 & 0,048 & 0,23 & 0,50 & 0,11 & 0,84 \\
\hline Ormosia arborea & 3 & 3 & 0,120 & 20,2 & 13,0 & 3,6 & 10,7 & 0,143 & 0,14 & 0,37 & 0,32 & 0,83 \\
\hline Vernonia discolor & 2 & 1 & 0,229 & 38,2 & 17,0 & 2,4 & 3,6 & 0,273 & 0,09 & 0,12 & 0,61 & 0,82 \\
\hline Cupania vernalis & 5 & 4 & 0,027 & 8,2 & 6,0 & 6,0 & 14,3 & 0,032 & 0,23 & 0,50 & 0,07 & 0,80 \\
\hline Psidium cattleianum & 5 & 4 & 0,023 & 7,3 & 5,5 & 6,0 & 14,3 & 0,027 & 0,23 & 0,50 & 0,06 & 0,79 \\
\hline Siphoneugena densiflora & 5 & 4 & 0,021 & 7,0 & 6,5 & 6,0 & 14,3 & 0,025 & 0,23 & 0,50 & 0,06 & 0,79 \\
\hline Nectandra nitidula & 3 & 3 & 0,093 & 18,7 & 14,3 & 3,6 & 10,7 & 0,111 & 0,14 & 0,37 & 0,25 & 0,76 \\
\hline Ilex conocarpa & 3 & 3 & 0,090 & 16,0 & 9,0 & 3,6 & 10,7 & 0,107 & 0,14 & 0,37 & 0,24 & 0,75 \\
\hline Piper cernuиm & 6 & 3 & 0,033 & 7,6 & 4,3 & 7,1 & 10,7 & 0,039 & 0,28 & 0,37 & 0,09 & 0,74 \\
\hline Euplassa incana & 4 & 4 & 0,021 & 7,8 & 5,5 & 4,8 & 14,3 & 0,025 & 0,19 & 0,50 & 0,05 & 0,74 \\
\hline Eugenia florida & 5 & 3 & 0,025 & 7,5 & 5,9 & 6,0 & 10,7 & 0,030 & 0,23 & 0,37 & 0,07 & 0,67 \\
\hline Garcinia gardneriana & 4 & 3 & 0,037 & 10,3 & 8,9 & 4,8 & 10,7 & 0,044 & 0,19 & 0,37 & 0,10 & 0,66 \\
\hline Eriotheca candolleana & 3 & 3 & 0,048 & 13,6 & 9,0 & 3,6 & 10,7 & 0,057 & 0,14 & 0,37 & 0,13 & 0,64 \\
\hline Myrsine lancifolia & 3 & 3 & 0,024 & 9,2 & 4,8 & 3,6 & 10,7 & 0,028 & 0,14 & 0,37 & 0,06 & 0,58 \\
\hline Lamanonia ternata & 2 & 2 & 0,087 & 22,9 & 11,5 & 2,4 & 7,1 & 0,104 & 0,09 & 0,25 & 0,23 & 0,57 \\
\hline Hirtella hebeclada & 3 & 3 & 0,015 & 7,9 & 5,2 & 3,6 & 10,7 & 0,018 & 0,14 & 0,37 & 0,04 & 0,55 \\
\hline Machaerium hirtum & 2 & 2 & 0,077 & 19,4 & 12,0 & 2,4 & 7,1 & 0,091 & 0,09 & 0,25 & 0,20 & 0,54 \\
\hline Sapium glandulatum & 3 & 2 & 0,058 & 15,2 & 8,5 & 3,6 & 7,1 & 0,069 & 0,14 & 0,25 & 0,15 & 0,54 \\
\hline Alibertia sessilis & 3 & 3 & 0,009 & 6,0 & 2,7 & 3,6 & 10,7 & 0,010 & 0,14 & 0,37 & 0,02 & 0,54 \\
\hline Cordia rufescens & 5 & 2 & 0,015 & 6,2 & 6,1 & 6,0 & 7,1 & 0,018 & 0,23 & 0,25 & 0,04 & 0,52 \\
\hline Piptocarpha macropoda & 2 & 2 & 0,053 & 18,3 & 7,0 & 2,4 & 7,1 & 0,063 & 0,09 & 0,25 & 0,14 & 0,48 \\
\hline
\end{tabular}


(cont.)

\begin{tabular}{|c|c|c|c|c|c|c|c|c|c|c|c|c|}
\hline Espécie & $\begin{array}{r}\mathrm{N} \\
\left(\mathrm{m}^{2}\right) \\
\end{array}$ & $\mathrm{P}$ & $\begin{array}{c}\mathrm{AB} \\
\left(\mathrm{m}^{2}\right)\end{array}$ & $\begin{array}{c}\mathrm{D} \\
(\mathrm{cm}) \\
\end{array}$ & $\begin{array}{c}\mathrm{h} \\
(\mathrm{m}) \\
\end{array}$ & $\begin{array}{c}\text { DA } \\
(1 / \mathrm{ha}) \\
\end{array}$ & $\begin{array}{l}\text { FA } \\
(\%) \\
\end{array}$ & $\begin{array}{c}\text { DoA } \\
\left(\mathrm{m}^{2} / \mathrm{ha}\right)\end{array}$ & $\begin{array}{l}\mathrm{DR} \\
(\%) \\
\end{array}$ & $\begin{array}{l}\text { FR } \\
(\%) \\
\end{array}$ & $\begin{array}{c}\text { DoR } \\
(\%) \\
\end{array}$ & VI \\
\hline Psidium guineense & 3 & 2 & 0,034 & 10,7 & 7,0 & 3,6 & 7,1 & 0,041 & 0,14 & 0,25 & 0,09 & 0,48 \\
\hline Erythroxylum cuneifolium & 3 & 2 & 0,027 & 10,1 & 3,5 & 3,6 & 7,1 & 0,032 & 0,14 & 0,25 & 0,07 & 0,46 \\
\hline Lithraea molleoides & 2 & 2 & 0,043 & 14,8 & 8,5 & 2,4 & 7,1 & 0,051 & 0,09 & 0,25 & 0,11 & 0,46 \\
\hline Sorocea bonplandii & 2 & 2 & 0,043 & 16,2 & 9,5 & 2,4 & 7,1 & 0,051 & 0,09 & 0,25 & 0,11 & 0,46 \\
\hline Prunus brasiliensis & 3 & 2 & 0,013 & 7,2 & 7,7 & 3,6 & 7,1 & 0,015 & 0,14 & 0,25 & 0,03 & 0,42 \\
\hline Rollinia sylvatica & 2 & 2 & 0,028 & 12,9 & 9,0 & 2,4 & 7,1 & 0,033 & 0,09 & 0,25 & 0,07 & 0,42 \\
\hline Myrocarpus frondosus & 1 & 1 & 0,089 & 33,7 & 15,0 & 1,2 & 3,6 & 0,106 & 0,05 & 0,12 & 0,24 & 0,41 \\
\hline Heteropterys byrsonimifolia & 4 & 1 & 0,028 & 8,4 & 5,1 & 4,8 & 3,6 & 0,033 & 0,19 & 0,12 & 0,07 & 0,38 \\
\hline Randia nitida & 2 & 2 & 0,014 & 9,2 & 5,8 & 2,4 & 7,1 & 0,017 & 0,09 & 0,25 & 0,04 & 0,38 \\
\hline Maytenus glazioviana & 2 & 2 & 0,006 & 6,4 & 7,8 & 2,4 & 7,1 & 0,008 & 0,09 & 0,25 & 0,02 & 0,36 \\
\hline Miconia pusilliflora & 2 & 2 & 0,006 & 6,1 & 6,8 & 2,4 & 7,1 & 0,007 & 0,09 & 0,25 & 0,02 & 0,36 \\
\hline Bacharis lymanii & 2 & 2 & 0,004 & 5,3 & 3,5 & 2,4 & 7,1 & 0,005 & 0,09 & 0,25 & 0,01 & 0,35 \\
\hline Nectandra grandiflora & 3 & 1 & 0,031 & 10,6 & 6,3 & 3,6 & 3,6 & 0,037 & 0,14 & 0,12 & 0,08 & 0,35 \\
\hline Styrax pohlii & 2 & 1 & 0,038 & 15,3 & 11,5 & 2,4 & 3,6 & 0,045 & 0,09 & 0,12 & 0,10 & 0,32 \\
\hline Ocotea brachybotra & 1 & 1 & 0,055 & 26,4 & 16,0 & 1,2 & 3,6 & 0,065 & 0,05 & 0,12 & 0,14 & 0,32 \\
\hline Aspidosperma cylindrocarpon & 1 & 1 & 0,054 & 26,1 & 13,0 & 1,2 & 3,6 & 0,064 & 0,05 & 0,12 & 0,14 & 0,31 \\
\hline Dalbergia villosa & 3 & 1 & 0,014 & 7,6 & 7,3 & 3,6 & 3,6 & 0,017 & 0,14 & 0,12 & 0,04 & 0,30 \\
\hline Galipea multiflora & 3 & 1 & 0,009 & 6,1 & 7,0 & 3,6 & 3,6 & 0,011 & 0,14 & 0,12 & 0,02 & 0,29 \\
\hline Psychotria deflexa & 3 & 1 & 0,006 & 5,2 & 2,2 & 3,6 & 3,6 & 0,008 & 0,14 & 0,12 & 0,02 & 0,28 \\
\hline Hieronyma alchorneoides & 1 & 1 & 0,041 & 22,9 & 9,0 & 1,2 & 3,6 & 0,049 & 0,05 & 0,12 & 0,11 & 0,28 \\
\hline Qualea jundiahy & 1 & 1 & 0,041 & 22,9 & 15,0 & 1,2 & 3,6 & 0,049 & 0,05 & 0,12 & 0,11 & 0,28 \\
\hline Diospyros hispida & 1 & 1 & 0,040 & 22,6 & 14,0 & 1,2 & 3,6 & 0,048 & 0,05 & 0,12 & 0,11 & 0,28 \\
\hline Prunus sellowii & 2 & 1 & 0,018 & 10,3 & 9,0 & 2,4 & 3,6 & 0,022 & 0,09 & 0,12 & 0,05 & 0,27 \\
\hline
\end{tabular}


(cont.)

\begin{tabular}{|c|c|c|c|c|c|c|c|c|c|c|c|c|}
\hline Espécie & $\begin{array}{c}\mathrm{N} \\
\left(\mathrm{m}^{2}\right) \\
\end{array}$ & $\mathrm{P}$ & $\begin{array}{c}\mathrm{AB} \\
\left(\mathrm{m}^{2}\right) \\
\end{array}$ & $\begin{array}{c}\mathrm{D} \\
(\mathrm{cm}) \\
\end{array}$ & $\begin{array}{c}\mathrm{h} \\
(\mathrm{m}) \\
\end{array}$ & $\begin{array}{c}\text { DA } \\
(1 / \mathrm{ha}) \\
\end{array}$ & $\begin{array}{l}\text { FA } \\
(\%) \\
\end{array}$ & $\begin{array}{c}\text { DoA } \\
\left(\mathrm{m}^{2} / \mathrm{ha}\right)\end{array}$ & $\begin{array}{l}\text { DR } \\
(\%) \\
\end{array}$ & $\begin{array}{l}\text { FR } \\
(\%) \\
\end{array}$ & $\begin{array}{l}\text { DoR } \\
(\%) \\
\end{array}$ & VI \\
\hline Daphnopsis fasciculata & 1 & 1 & 0,033 & 20,4 & 6,5 & 1,2 & 3,6 & 0,039 & 0,05 & 0,12 & 0,09 & 0,26 \\
\hline Myrsine coriacea & 2 & 1 & 0,014 & 9,1 & 10,5 & 2,4 & 3,6 & 0,016 & 0,09 & 0,12 & 0,04 & 0,25 \\
\hline Salacia elliptica & 2 & 1 & 0,013 & 9,2 & 4,8 & 2,4 & 3,6 & 0,016 & 0,09 & 0,12 & 0,04 & 0,25 \\
\hline Tibouchina stenocarpa & 2 & 1 & 0,005 & 5,6 & 2,3 & 2,4 & 3,6 & 0,006 & 0,09 & 0,12 & 0,01 & 0,23 \\
\hline Cordia ecalyculata & 1 & 1 & 0,022 & 16,5 & 7,5 & 1,2 & 3,6 & 0,026 & 0,05 & 0,12 & 0,06 & 0,23 \\
\hline Nephelea sternbergii & 1 & 1 & 0,021 & 16,2 & 2,0 & 1,2 & 3,6 & 0,025 & 0,05 & 0,12 & 0,05 & 0,23 \\
\hline Aspidosperma parvifolium & 1 & 1 & 0,017 & 14,6 & 12,0 & 1,2 & 3,6 & 0,020 & 0,05 & 0,12 & 0,04 & 0,22 \\
\hline Cecropia pachystachya & 1 & 1 & 0,013 & 12,7 & 9,0 & 1,2 & 3,6 & 0,015 & 0,05 & 0,12 & 0,03 & 0,20 \\
\hline Acosmium dasycarpum & 1 & 1 & 0,009 & 10,5 & 2,0 & 1,2 & 3,6 & 0,010 & 0,05 & 0,12 & 0,02 & 0,19 \\
\hline Ternstroemia alnifolia & 1 & 1 & 0,009 & 10,5 & 8,0 & 1,2 & 3,6 & 0,010 & 0,05 & 0,12 & 0,02 & 0,19 \\
\hline Miconia chartacea & 1 & 1 & 0,006 & 8,9 & 9,0 & 1,2 & 3,6 & 0,007 & 0,05 & 0,12 & 0,02 & 0,19 \\
\hline Symplocos pubescens & 1 & 1 & 0,006 & 8,6 & 10,0 & 1,2 & 3,6 & 0,007 & 0,05 & 0,12 & 0,02 & 0,19 \\
\hline Endlicheria paniculata & 1 & 1 & 0,005 & 8,0 & 4,0 & 1,2 & 3,6 & 0,006 & 0,05 & 0,12 & 0,01 & 0,18 \\
\hline Leandra scabra & 1 & 1 & 0,005 & 7,6 & 3,0 & 1,2 & 3,6 & 0,006 & 0,05 & 0,12 & 0,01 & 0,18 \\
\hline Croton floribundus & 1 & 1 & 0,004 & 7,3 & 9,0 & 1,2 & 3,6 & 0,005 & 0,05 & 0,12 & 0,01 & 0,18 \\
\hline Piper gaudichaudianum & 1 & 1 & 0,004 & 7,3 & 5,0 & 1,2 & 3,6 & 0,005 & 0,05 & 0,12 & 0,01 & 0,18 \\
\hline Siparuna apiosyce & 1 & 1 & 0,004 & 7,0 & 3,0 & 1,2 & 3,6 & 0,005 & 0,05 & 0,12 & 0,01 & 0,18 \\
\hline Platypodium elegans & 1 & 1 & 0,004 & 6,7 & 5,0 & 1,2 & 3,6 & 0,004 & 0,05 & 0,12 & 0,01 & 0,18 \\
\hline Drypetes sessiliflora & 1 & 1 & 0,003 & 6,4 & 3,5 & 1,2 & 3,6 & 0,004 & 0,05 & 0,12 & 0,01 & 0,18 \\
\hline Chionanthus arboreus & 1 & 1 & 0,003 & 6,1 & 7,0 & 1,2 & 3,6 & 0,003 & 0,05 & 0,12 & 0,01 & 0,18 \\
\hline Syagrus flexиosa & 1 & 1 & 0,002 & 5,4 & 2,0 & 1,2 & 3,6 & 0,003 & 0,05 & 0,12 & 0,01 & 0,18 \\
\hline Guapira tomentosa & 1 & 1 & 0,002 & 5,4 & 4,0 & 1,2 & 3,6 & 0,003 & 0,05 & 0,12 & 0,01 & 0,18 \\
\hline Eugenia pluriflora & 1 & 1 & 0,002 & 5,4 & 5,0 & 1,2 & 3,6 & 0,003 & 0,05 & 0,12 & 0,01 & 0,18 \\
\hline
\end{tabular}


(cont.)

\begin{tabular}{|c|c|c|c|c|c|c|c|c|c|c|c|c|}
\hline Espécie & $\begin{array}{r}\mathrm{N} \\
\left(\mathrm{m}^{2}\right)\end{array}$ & $\mathrm{P}$ & $\begin{array}{l}\mathrm{AB} \\
\left(\mathrm{m}^{2}\right) \\
\end{array}$ & $\begin{array}{c}\mathrm{D} \\
(\mathrm{cm}) \\
\end{array}$ & $\begin{array}{c}\mathrm{h} \\
(\mathrm{m}) \\
\end{array}$ & $\begin{array}{c}\text { DA } \\
(1 / \mathrm{ha}) \\
\end{array}$ & $\begin{array}{l}\text { FA } \\
(\%) \\
\end{array}$ & $\begin{array}{c}\text { DoA } \\
\left(\mathrm{m}^{2} / \mathrm{ha}\right)\end{array}$ & $\begin{array}{l}\text { DR } \\
(\%) \\
\end{array}$ & $\begin{array}{l}\text { FR } \\
(\%) \\
\end{array}$ & $\begin{array}{l}\text { DoR } \\
(\%) \\
\end{array}$ & VI \\
\hline Tabebuia ochracea & 1 & 1 & 0,002 & 5,1 & 2,0 & 1,2 & 3,6 & 0,002 & 0,05 & 0,12 & 0,01 & 0,18 \\
\hline Ouratea semisserrata & 1 & 1 & 0,002 & 5,1 & 5,0 & 1,2 & 3,6 & 0,002 & 0,05 & 0,12 & 0,01 & 0,18 \\
\hline Myrcia multiflora & 1 & 1 & 0,002 & 5,1 & 4,5 & 1,2 & 3,6 & 0,002 & 0,05 & 0,12 & 0,01 & 0,18 \\
\hline Miconia pepericarpa & 1 & 1 & 0,002 & 5,1 & 2,5 & 1,2 & 3,6 & 0,002 & 0,05 & 0,12 & 0,01 & 0,18 \\
\hline Totais & 2145 & & 37,822 & & & 2553,6 & & 45,03 & 100 & 100 & 100 & 300 \\
\hline
\end{tabular}


fica entre as áreas florestais do alto rio Grande teriam maior influência na semelhança florística entre elas que o fato de a floresta ser ripária ou não, pois as florestas ripárias $(\mathrm{CM}, \mathrm{PB}, \mathrm{IT}, \mathrm{BS}, \mathrm{MD})$ não se diferenciaram das demais (TD e LV). É provável que esta mesma explicação seja aplicável às florestas estacionais semideciduais submontanas, já que, também neste caso, florestas ripárias e não ripárias se apresentaram misturadas no gráfico da DCA (figura 4).

As florestas ombrófilas densas montanas analisadas não puderam ser consideradas como um grupo único, já que se apresentaram muito diferenciadas entre si, principalmente no primeiro eixo da DCA. As áreas da Serra do Japi (JU) e de Atibaia (AT) seriam floristicamente mais associadas às florestas estacionais semideciduais submontanas e montanas, respectivamente, do que à Serra da Cantareira (floresta ombrófila densa montana). São José dos Campos ocuparia uma posição intermediária entre a Serra da Cantareira, uma floresta ombrófila densa montana, e as florestas estacionais semideciduais submontanas e montanas. A classificação fisionômica das florestas ocorrentes próximas às vertentes interiores da Serra do Mar tem sido uma questão bastante debatida, sendo essas florestas freqüentemente consideradas formações transicionais entre as florestas ombrófilas densas montanas e as florestas estacionais semideciduais submontanas (Baitello et al. 1992).

O primeiro eixo da DCA apresentou-se fortemente associado à intensidade da estacionalidade climática. As florestas de climas mais estacionais (semideciduais e mais distantes do litoral) tenderam a agrupar-se no lado esquerdo do gráfico e as áreas com estação seca menos marcante (ombrófilas) tenderam para o lado direito. O segundo eixo do DCA foi relacionado, pelo menos parcialmente, com os efeitos da altitude na composição florística das áreas. Quase todas as florestas estacionais semideciduais submontanas com altitudes abaixo de $650 \mathrm{~m}$ foram separadas das áreas das demais fisionomias, todas acima de $750 \mathrm{~m}$.

Levantamento fitossociológico - Os índices de diversidade de Shannon-Wiener (H') das cinco áreas comparadas, incluindo Camargos (tabela 4), foram altos, em torno de 4 (Kent \& Coker 1992). Entre os principais fatores que poderiam estar contribuindo para 
Tabela 4. Valores de área amostrada (A); número de indivíduos amostrados $(\mathrm{N})$; número de espécies amostradas (S); índice de diversidade de Shannon-Wiener (H'); e índice de eqüitabilidade de Pielou (J') para Camargos (CM) e quatro áreas da região do alto rio Grande: Poço Bonito (PB), Bom Sucesso/Macaia (BS), Itutinga (IT) e Madre de Deus de Minas. (MD).Tipos de floresta: FESM = Floresta estacional semidecidual montana; $\mathrm{FG}=$ Floresta de galeria.

\begin{tabular}{lcccccc}
\hline Área & Tipo de Floresta & A (ha) & N (indiv.) & $\mathrm{S}^{\text {(n }}$ de spp.) & $\mathrm{H}^{\prime}$ (nats.ind ${ }^{-1}$ ) & J' \\
\hline CM & FG & 0,84 & 2145 & 141 & 3,924 & 0,793 \\
PB & FESM & 0,48 & 1045 & 119 & $4,204^{* *}$ & 0,880 \\
BS & FESM & 0,54 & 1615 & 157 & $4,331^{* *}$ & 0,857 \\
IT & FG & 0,94 & 3152 & 176 & 3,896 n.s. & 0,753 \\
MD & FESM & 0,97 & 1539 & 111 & $3,790^{* *}$ & 0,810 \\
\hline
\end{tabular}

** Diferença significativa a 1\% de probabilidade em relação a Camargos (CM). n.s. Diferença não significativa em relação a Camargos (CM).

a diversidade em Camargos, encontra-se, certamente, a heterogeneidade ambiental determinada pela borda, meio e margem do córrego, habitats muito variáveis em termos de regime de água do solo e luminosidade (van den Berg \& Oliveira-Filho 1999). As outras áreas comparadas também incluíram grande heterogeneidade ambiental, especialmente as de maiores índices de diversidade de espécies, Bom Sucesso (BS) e Poço Bonito (PB). Estas apresentaram variações internas mais marcantes de fertilidade de solo (Bom Sucesso) ou topografia (Poço Bonito), que as demais (Oliveira-Filho et al. 1994d). H' de Camargos não diferiu estatisticamente de Itutinga (IT), mas foi significativamente diferente das outras áreas. CM e IT são duas áreas

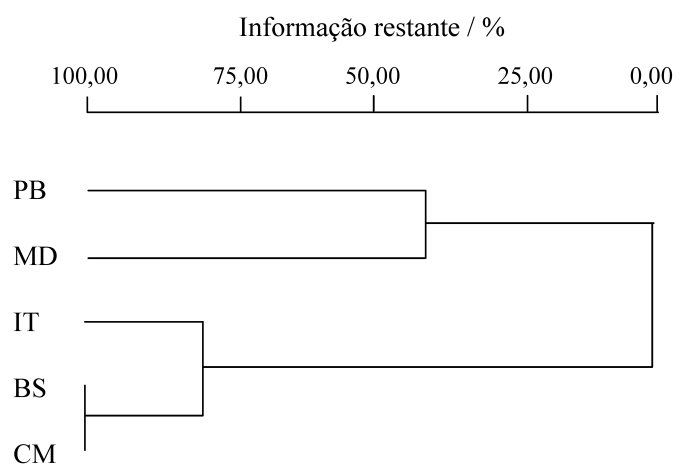

Figura 5. Dendrograma produzido a partir das distâncias euclidianas entre cinco áreas de floresta do alto Rio Grande. A escala corresponde à informação restante após a formação de cada grupo (McCune \& Mefford 1997). PB = Poço Bonito; BS = Bom Sucesso, IT = Itutinga; $\mathrm{CM}=$ Camargos $; \mathrm{MD}=$ Madre de Deus de Minas. próximas geograficamente e bastante semelhantes em termos ambientais (ver abaixo), tendo sido ambas classificadas como florestas de galeria. Ambas apresentaram umas poucas espécies com um grande número de indivíduos, que dominaram a fisionomia, resultando em uma baixa equabilidade (J'). Madre de Deus (MD) apresentou uma diversidade menor que Camargos, devido, provavelmente, ao menor número de espécies encontradas. A diversidade de Bom Sucesso (BS) foi mais elevada, provavelmente devido tanto ao maior número de espécies quanto à maior equabilidade. Já no caso de Poço Bonito (PB), a maior diversidade resultaria da mais alta equabilidade, visto que a riqueza de espécies foi menor que a de Camargos. Assim, tanto em BS como em PB não ocorreu a dominância marcante de umas poucas espécies, como em IT e CM.

Entre as florestas do alto rio Grande, Itutinga (IT) foi a que apresentou a menor dissimilaridade com Camargos, provavelmente devido tanto à grande proximidade geográfica (não mais de $500 \mathrm{~m}$ ) quanto a características semelhantes, como: ambas circundarem as cabeceiras de córregos; serem seus solos predominantes bastante semelhantes (Cambissolos), com propriedades químicas, físicas e conteúdo de matéria orgânica bem próximos (van den Berg \& Oliveira-Filho 1999); limitarem-se com a vegetação de campo limpo de altitude; e possuírem feições topográficas parecidas.

É provável que Madre de Deus (MD) e, principalmente, Poço Bonito (PB) tenham se diferenciado das demais áreas devido a diferenças nas propriedades de seu solo. Essas duas áreas apresentaram solos caracteristicamente mais arenosos que as de- 
mais. No caso do Poço Bonito, além das diferenças texturais, os teores de fósforo, matéria orgânica e alumínio foram mais altos e os teores de cálcio e magnésio mais baixos que nas demais áreas. Dentre essas propriedades de solo, o fósforo é um importante fator na diferenciação estrutural de florestas tropicais (Askew et al. 1971, Gartlan et al. 1986, Newbery et al. 1986, Oliveira-Filho et al. 1994b). Já os solos de Bom Sucesso (BS) e, principalmente, Itutinga (IT) foram bastante semelhantes ao de Camargos (vide Oliveira-Filho et al. 1994d e van den Berg \& Oliveira-Filho 1999 para os dados de solo).

Agradecimentos - Ao Conselho Nacional de Pesquisa (CNPq), pelo suporte financeiro a este projeto. Também estendemos nossos agradecimentos aos colegas José Caixeta, Prof. Marco Aurélio Fontes, Luís Marcelo Carvalho (Passarinho), Santos D’Ângelo, Charles Silva, e, em particular, Adelson Oliveira, pela valiosa ajuda durante os trabalhos de campo. Agradecemos ao Prof. Dr. Jorge Tamashiro, pela contribuição na identificação de parte do material botânico coletado e ao Prof. Dr. Nilton Curi, pela classificação e descrição dos solos da área de estudos.

\section{Referências bibliográficas}

ASKEW, G.P., MOFFATT, D.J., MONTGOMERY, R.F. \& SEARL, P.L. 1971. Soils, and soil moisture as factors influencing the distribution of the vegetation formations of the Serra do Roncador, Mato Grosso. In III simpósio sobre cerrado (M.G. Ferri, coord.). Edgar Blucher, São Paulo, p.150-160.

BAITELLO, J.B., PASTORE, J.A., AGUIAR, O.T., SERIO, F.C. \& SILVA, C.E.F. 1988. A vegetação arbórea do Parque Estadual do Morro do Diabo, município de Teodoro Sampaio, estado de São Paulo. Acta Botanica Brasilica 2:221-230.

BAITELLO, J.B., AGUIAR, O.T., ROCHA, F.T., PASTORE, J.A. \& ESTEVES, R. 1992. Florística e fitossociologia do estrato arbóreo de um trecho da Serra da Cantareira (Núcleo Pinheirinho), SP. In Anais do II congresso nacional sobre essências nativas. Revista do Instituto Florestal 4:291-297.

BARBOSA, L.M. (coord.) 1989. Anais do simpósio sobre mata ciliar. Fundação Cargill, Campinas.

BERTONI, J.E.A. \& MARTINS, F.R. 1987. Composição florística de uma floresta ripária na Reserva Estadual de Porto Ferreira (SP). Acta Botanica Brasilica 1:17-26.

BERTONi, J.E.A., MARTINS, F.R., MORES, J.L. \& SHEPHERD, G.J. 1988. Composição florística e estrutura fitossociológica do Parque Estadual de Vaçununga, Santa Rita do Passa Quatro, SP - Gleba Praxedes. Boletim Técnico do Instituto Florestal 42:149-170.

BROWER, J.E. \& ZAR, J.H. 1984. Field and laboratory methods for general ecology. Wm. C. Brown Pub., Dubuque.

CAMPOS, J.C.C. \& HEINSDSDIJK, D. 1970. A floresta do Morro do Diabo. Silvicultura em São Paulo 7:43-58.
CARVALHO, D.A., OLIVEIRA-FILHO, A.T., VILELA, E.A. \& GAVILANES, M.L. 1992. Flora arbustivo-arbórea das matas ciliares do alto rio Grande (MG). 1 - mata de Macaia (Bom Sucesso). In Anais do II congresso nacional sobre essências nativas. Revista do Instituto Florestal 4:274-282.

CARVALHO, D.A., OLIVEIRA-FILHO, E.A., VILELA, E.A. \& GAVILANES, M.L. 1995. Estrutura fitossociológica de mata ripária do alto rio Grande (Bom Sucesso/MG). Revista Brasileira de Botânica 18:39-49.

CAUSTON, D.R. 1988. An introduction to vegetation analysis, principles, practice and interpretation. Unwin Hyman, London.

CAVASSAN, O., CESAR, O. \& MARTINS, F.R. 1984. Fitossociologia da vegetação arbórea da Reserva Estadual de Bauru, estado de São Paulo. Revista Brasileira de Botânica 7:91-106.

CESAR, O. \& LEITÃO-FILHO, H.F. 1990a. Estudo fitossociológico de mata mesófila semidecídua na Fazenda Barreiro Rico, município de Anhembi, SP. Revista Brasileira de Biologia 50:443-452.

CESAR, O. \& LEITÃO-FILHO, H.F. 1990b. Estudo florístico quantitativo de mata mesófila semidecídua na Fazenda Barreiro Rico, município de Anhembi, SP. Revista Brasileira Biologia 50:133-147.

CESP - COMPANHIA ENERGÉTICA DE SÃO PAULO. 1987. Considerações sobre as matas ciliares e a implantação de reflorestamento misto nas margens de rios e reservatórios. CESP, São Paulo.

COSTA, L.G.S., PINA-RODRIGUES, F.C.M. \& JESUS, R.M. 1992. Grupos ecológicos e a dispersão de sementes de espécies arbóreas em trecho da floresta tropical na Reserva Florestal de Linhares, ES. In Anais do II congresso nacional sobre essências nativas. Revista do Instituto Florestal 4:303-305.

EIDT, R.C. 1968. The climatology of South America. In Biogeography and ecology in South America (E.J. Fittkau, J. Illies, H. Klinge, G.H. Schwabe \& H. Sioli, eds.), v.1 W. Junk Pub., The Hague, p.54-81.

FELFILI, J.M. (coord.) 1990. Bigeografia do bioma cerrado: Zoneamento dos recursos bióticos visando manejo e conservação - Relatório final: Chapada Pratinha. Universidade de Brasília, Brasília.

FELFILI, J.M. 1994. Floristic composition and phytosociology of the gallery forest alongside the Gama stream in Brasília, DF, Brazil. Revista Brasileira de Botânica 17:1-11.

GARTLAN, J.S., NEWBERRY, D.M., THOMAS, D.W. \& WATERMAN, P.G. 1986. The influence of topography and soil phosphorus on the vegetation of Korup Reserve, Cameroun. Vegetatio 65:131-148.

GAUCH, H.G. 1982. Multivariate analysis in community ecology. Cambridge University Press, Cambridge.

GAVILANES, M.L., BRANDÃO, M., OLIVEIRA-FILHO, A.T., ALMEIDA, R.J., MELLO, J.M. \& AVEZUM, F.F. 1992a. Flórula da Reserva Biológica Municipal do Poço Bonito, Lavras, MG. II - Formação florestal. Daphne 2:14-26. 
GAVILANES, M.L., OLIVEIRA-FILHO, A.T., CARVALHO, D.A. \& VILELA, E.A. 1992b. Flora arbustivo-arbórea das matas ciliares do alto rio Grande (MG). 2 - mata de Madre de Deus de Minas. In Anais do II congresso nacional sobre essências nativas. Revista do Instituto Florestal 4:253-290.

GIBBS, P.E. \& LEITÃO-FILHO, H.F. 1978. Floristic composition of an area of gallery forest near Mogi Guaçu, State of São Paulo, S.E. Brazil. Revista Brasileira de Botânica 1:151-156.

GIBBS, P.E., LEITÃO-FILHO, H.F. \& ABBOT, R.J. 1980. Application of the point-centred quarter method in a floristic survey of an area of galery forest at Mogi-Guaçu, SP, Brazil. Revista Brasileira de Botânica 3:17-22.

GROMBONE, M.T., BERNACCI, L.C., MEIRA-NETO, J.A., TAMASHIRO, J.Y. \& LEITÃO-FILHO, H.F. 1990. Estrutura fitossociológica da floresta semidecídua de altitude do Parque Municipal da Grota Funda (Atibaia estado de São Paulo). Acta Botanica Brasilica 4:47-64.

IBGE - Insituto Brasileiro de Geografia Estatística. 1993. Mapa de vegetação do Brasil. Fundação Instituto Brasileiro de Geografia e Estatística, Rio de Janeiro.

KENT, M. \& COKER, P. 1992. Vegetation description and analysis, a practical approach. Belhaven Press, London.

MANTOVANI, W. 1989. Conceituação e fatores condicionantes. In Anais do simpósio sobre mata ciliar (L.M. Barbosa, coord.). Fundação Cargill, Campinas, p.11-19.

MANTOVANI, W., CATHARINO, E.L.M. \& BORGES, H.B.N. 1986. Composição florística e fitossociológica, Sub-projeto 2. In Estudo para implantação de matas ciliares de proteção na bacia hidrográfica do Passa Cinco visando a utilização para abastecimento urbano (P.Y. Kageyma, coord.). DAEE, ESALQ/USP, Piracicaba.

MANTOVANI, W., ROSSI, L., ROMANIUC-NETO, S., ASSAD-LUDEWIGIS, I.W., WANDERLEY, M.G.L., MELO, M.M.R. \& TOLEDO, C.B. 1989. Estudo fitossociológico de áreas de mata ciliar em Mogi-Guaçu, SP, Brasil. In Anais do simpósio sobre mata ciliar (L.M. Barbosa, coord.). Fundação Cargill, Campinas, p.235-267.

MARCHIORI, A.C.C., NASSAR JR., F. \& DEMATTÊ, M.E.S.P. 1992. Levantamento florístico e fitossociológico do estrato arbóreo de mata residual do Viveiro Experimental da FCAV-UNESP, Jaboticabal, SP. In Anais do VIII congresso da Sociedade Botânica de São Paulo. SBSP, Campinas, p.121-131.

MARTINS, F.R. 1991. Estrutura de uma floresta mesófila. Editora da UNICAMP, Campinas.

McCUNE, B. \& MEFFORD, M.J. 1997. Multivariate analysis of ecological data. Version 3.12. MjM Software, Gleneden Beach.

MEIRA-NETO, J.A.A., BERNACCI, L.C., GROMBONE, M.T., TAMASHIRO, J.Y. \& LEITÃO-FILHO, H.F. 1989. Composição florística da floresta semidecídua de altitude do Parque Municipal da Grota Funda (Atibaia, estado de São Paulo). Acta Botanica Brasilica 3:51-74.

MOTA, A.L.P. 1984. Estudo dendrológico na mata da Casca d'Anta - Parque Nacional da Serra da Canastra, MG. Dissertação de mestrado, Universidade Federal de Viçosa, Viçosa.

MUELLER-DOMBOIS, D. \& ELLENBERG, H. 1974. Aims and methods of vegetation ecology. Wiley and Sons, New York.
NEWBERY, D.M.C.C., GARTLAN, J.S., MCKEY, D.B. \& WATERMAN, P.G. 1986. The influence of drainage and soil phosphorus on the vegetation of Douala-Edea Forest reserve, Cameroun. Vegetatio 65:149-162.

OLIVEIRA-FILHO, A.T. \& RATTER, J.A. 1994. Database: woody flora of 106 forest areas of eastern tropical South America. Royal Botanic Garden, Edinburgh.

OLIVEIRA-FILHO, A.T., ALMEIDA, R.J., MELLO, J.M. \& GAVILANES, M.L. 1994a. Estrutura fitossociológica e variáveis ambientais em um trecho da mata ciliar do córrego dos Vilas Boas, Reserva Biológica do Poço Bonito, Lavras (MG). Revista Brasileira de Botânica 17:67-85.

OLIVEIRA-FILHO, A.T., CURI, N., VILELA, E.A. \& CARVALHO, D.A. 1997. Tree species distribution along soil catenas in a riverside semideciduous forest in southeastern Brazil. Flora 192:47-64.

OLIVEIRA-FILHO, A.T., VILELA, E.A., CARVALHO, D.A. \& GAVILANES, M.L. 1994b. Effect of soils and topography on the distribution of tree species in a tropical riverine forest in Southeastern Brazil. Journal of Tropical Ecology 10:233-258.

OLIVEIRA-FILHO, A.T., VILELA, E.A., CARVALHO, D.A. \& GAVILANES, M.L. 1994c. Differentiation of streamside and upland vegetation in an area of montane semideciduous forest in southeastern Brazil. Flora 189:287-305.

OLIVEIRA-FILHO, A.T., VILELA, E.A., CARVALHO, D.A. \& GAVILANES, M.L. 1995. Estudos florísticos e fitossociológicos em remanescentes de matas ciliares do alto e médio rio Grande. Companhia Energética de Minas Gerais (CEMIG), Belo Horizonte.

OLIVEIRA-FILHO, A.T., VILELA, E.A., GAVILANES, M.L. \& CARVALHO, D.A. 1994d. Comparison of the woody flora and soils of six areas of montane semideciduous forest in Southern Minas Gerais, Brazil. Edinburgh Journal of Botany 51:355-389.

OLIVEIRA-FILHO, A.T., VILELA, E.A., GAVILANES, M.L. \& CARVALHO, D.A. 1994e. Effect of flooding regime and understorey bamboos on the physiognomy and tree species composition of a tropical semideciduous forest in Southeastern Brazil. Vegetatio 113:99-124.

PAGANO, S.N. \& LEITÃO-FILHO, H.F. 1987. Composição florística do estrato arbóreo da mata mesófila semidecídua no município de Rio Claro (estado de São Paulo). Revista Brasileira de Botânica 10:37-47.

PINTO, M.M. 1989. Levantamento fitossociológico de uma mata residual: campus de Jaboticabal da UNESP. Dissertação de mestrado, Universidade Estadual Paulista Júlio de Mesquita Filho, Jaboticabal.

REDFORD, K.H. \& FONSECA, G.A.B. 1986. The role of gallery forests in the zoogeography of the cerrado's non-volant mamalian fauna. Biotropica 18:126-135.

RODRIGUES, R.R. 1986. Levantamento florístico e fitossociológico das matas da Serra do Japi, Jundiaí, SP. Dissertação de mestrado, Universidade Estadual de Campinas, Campinas.

RODRIGUES, R.R. 1991. Análise de um remanescente de vegetação natural às margens do Rio Passa Cinco, Ipeúna, SP. Tese de doutorado, Universidade Estadual de Campinas, Campinas. 
RODRIGUES, R.R., MORELLATO, L.P.C., JOLY, C.A. \& LEITÃO-FILHO, H.F. 1989. Estudo florístico e fitossociológico em um gradiente altitudinal de mata estacional mesófila semidecídua na serra do Japi, Jundiaí. Revista Brasileira de Botânica 12:71-84.

SCHIAVINI, I. 1992. Estrutura das comunidades arbóreas de mata de galeria da Estação Ecologica do Panga (Uberlândia, MG). Tese de doutorado, Universidade Estadual de Campinas, Campinas.

SILVA, A.F. 1989. Composição florística e estrutura fitossociológica do estrato arbóreo da Reserva Florestal Professor Augusto Ruschi, São José dos Campos, SP. Tese de doutorado, Universidade Estadual de Campinas, Campinas.
VAN DEN BERG, E. \& OLIVEIRA-FILHO, A.T. 1999. Spatial partitioning among tree species within an area of tropical montane gallery forest in South-eastern Brazil. Flora 194:249-266.

VELOSO, H.P., RANGEL-FILHO, A.L.R. \& LIMA, J.C.A 1991. Classificação da vegetação brasileira adaptada a um sistema universal. Instituto Brasileiro de Geografia e Estatística, Rio de Janeiro.

VILELA, E.A., OLIVEIRA-FILHO, A.T., GAVILANES, M.L. \& CARVALHO, D.A. 1993. Espécies de matas ciliares com potencial para estudos de revegetação no alto rio Grande, Sul de Minas. Revista Árvore 17:117-128.

ZAR, J. H. 1984. Biostatistical analysis. $2^{\text {nd }}$ ed. Prentice-Hall, Englewood Cliffs. 